\title{
Progress and Summary of Photodarkening in Rare Earth Doped Fiber
}

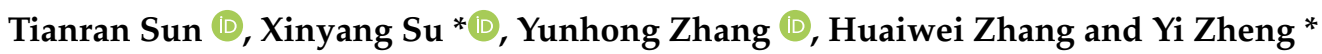 \\ School of Science, Beijing Jiaotong University, Beijing 100044, China; 18118043@bjtu.edu.cn (T.S.); \\ 19118047@bjtu.edu.cn (Y.Z.); 18126233@bjtu.edu.cn (H.Z.) \\ * Correspondence: suxinyang@bjtu.edu.cn (X.S.); yizheng@bjtu.edu.cn (Y.Z.)
}

Citation: Sun, T.; Su, X.; Zhang, Y.; Zhang, H.; Zheng, Y. Progress and Summary of Photodarkening in Rare Earth Doped Fiber. Appl. Sci. 2021, 11, 10386. https://doi.org/10.3390/ app112110386

Academic Editor: Christophe Finot

Received: 30 September 2021

Accepted: 3 November 2021

Published: 5 November 2021

Publisher's Note: MDPI stays neutral with regard to jurisdictional claims in published maps and institutional affiliations.

Copyright: (c) 2021 by the authors. Licensee MDPI, Basel, Switzerland. This article is an open access article distributed under the terms and conditions of the Creative Commons Attribution (CC BY) license (https:/ / creativecommons.org/licenses/by/ $4.0 /)$.
Abstract: In this paper, we summarize the research on photodarkening in optical fibers. The causes of photodarkening in fiber, the influence of photodarkening on fiber laser, the experimental device of photodarkening, and the mathematical model used to study the phenomenon of photodarkening are described in detail. At the end of the paper, we summarize the means and methods to suppress photodarkening.

Keywords: photodarkening (PD); excited-state absorption (ESA); energy transfer upconversion (ETU); avalanche upconversion; cooperative luminescence; photobleaching (PB); thermal-bleaching (TB); refractive index change (RIC); color center

\section{Introduction}

Fiber laser has a wide range of application prospects in industrial processing, advanced manufacturing, national defense, and other fields due to its advantages of high efficiency, high stability, high beam quality, and easiness to expand to high power. Photodarkening (PD) is an important problem in fiber lasers. PD is characterized by broadband absorption centered on the wavelength of visible light, which increases with working time, and the performance of PD is also related to the preparation method of active optical fiber [1-7]. Aging is based on the continuous competition between PD and bleaching.

\subsection{Research Progress of Thulium-Doped Fiber (TDF) Photodarkening}

Since 1988, Millar et al. [8] found the phenomenon of PD in Tm-doped quartz fiber, the effect of PD has attracted wide attention. Because there is a certain correlation between PD and laser mode, how to suppress the PD and excitation mode disturbance of high-power fiber laser has become an important topic. When the TDF is exposed to strong blue light $(475 \mathrm{~nm})$, the visible and near-infrared transmission spectrum of the fiber is significantly reduced, and it is easy for the $\mathrm{Ge}^{4+}$ ions in the fiber to produce two-photon absorption close to the pump light. In 1993, Brocklesby et al. [9] compared Tm-doped silica fiber and Tm-doped germanosilicate fiber; it was found that thulium ion itself affects the generation of PD. In the same year, Broer et al. [10] found that Tm-doped silica fiber appeared PD when excited by a near-infrared laser $(1064 \mathrm{~nm})$. He attributed this phenomenon to ultraviolet and visible light produced by photon avalanche upconversion. In 1995, Barber et al. [11] found the PD effect introduced by near-infrared laser in Tm-doped fluorinated fiber. The typical phenomenon is that a strong loss is found in the visible light area after the laser radiation of $1140 \mathrm{~nm}$. It is believed that the generation of the color center is the cause of strong loss. In 1995, Laperle et al. [4] reported the PD-induced absorption of four kinds of Tm-doped ZBLAN fibers under a $1.12 \mu \mathrm{m}$ laser. The results show that the relationship between the darkening rate and the pump intensity is quartic and strongly depends on the concentration of $\mathrm{Tm}^{3+}$ ions. The PD-induced absorption was mainly found in the ultraviolet-visible part of the spectrum, and there are some parts of the absorption spectra extending slightly longer than $1 \mu \mathrm{m}$ in the near-infrared. In 1997, Laperle et al. [12] 
observed the photobleaching (PB) of Tm-doped ZBLAN fiber after short-time irradiation under visible light. The bleaching process can be described by the stretched-exponential function of time. Incomplete and slow color center recovery was observed in previously bleached fibers, indicating at least two types of defects exist. In 2010, Frith et al. [13] analyzed the reason for blue light produced by $790 \mathrm{~nm}$ pumped TDF and the influence of fiber components. The loss of power of TDF laser in thousands of working hours was less than $1 \%$ through component optimization. At the same time, increasing the $\mathrm{Tm}^{3+}$ doping concentration can effectively reduce the upconversion efficiency and the PD of the optical fiber, and it was found that the PD rate was directly proportional to the number of concentrated ions in energy level ${ }^{3} \mathrm{H}_{4}$. In 2020, Yin-Zi Liu et al. [14] demonstrated the PD phenomenon in TDF core-pumped by a $1080 \mathrm{~nm}$ laser and the bleaching effect of deuterium $\left(\mathrm{D}_{2}\right)$ loading on photodarkened TDF.

\subsection{Research Progress of Ytterbium-Doped Fiber (YDF) Photodarkening}

Although the discovery and research of PD in TDF is earlier than that in YDF, at present, the research on the PD effect and laser mode instability of rare earth doped fiber is mainly aimed at YDF laser [15]. Compared with $\mathrm{Tm}^{3+}$ ion, $\mathrm{Yb}^{3+}$ ion has a great difference in energy level structure. $\mathrm{Yb}^{3+}$ ion belongs to a simple energy level structure, with no excited-state absorption, long fluorescence life, and small quantum defects [16].

In 1997, Paschotta et al. [17] found pump-induced absorption in Yb-doped silica fiber. In 2005, Koponen et al. [18] first called it PD in YDF research. In 2007, Chavez et al. [1] reported experiments showing new characteristics of $\mathrm{PD}$ and $\mathrm{PB}$ of high concentration $\mathrm{Yb}$ doped silicon fibers exposed to $977 \mathrm{~nm}$ and $543 \mathrm{~nm}$ in core irradiation. The results showed that pumping the fiber at $977 \mathrm{~nm}$ would increase the absorption in a wide spectral range from 400 to $1000 \mathrm{~nm}(\mathrm{PD})$, and simultaneously decrease the resonant $\left(\mathrm{Yb}^{3+}\right)$ absorption co-efficient near $1 \mu \mathrm{m}$ (PB). In 2007, Jetschke et al. [19] first observed the partial bleaching of PD loss by pump power itself. The effects of temperature and pump wavelength on the equilibrium state of additional loss were studied. From the dependence of the measured rate constant on the density of excited $\mathrm{Yb}$ ions, they concluded that an average of 3 to 4 excited $\mathrm{Yb}$ ions produced or bleached a color center, which was the cause of additional loss. Manek-Hönninger et al. [2] studied the temporal evolution of the PD effect in an $\mathrm{Yb}$-doped silica large-mode-area (LMA) fiber. When the fiber was exposed to a $980 \mathrm{~nm}$ pumped laser, the absorption spectrum showed an increase in the visible and near-infrared spectrum. In 2007, Yoo et al. [3] studied the evolution of the PD effect with time in $\mathrm{Yb}$-doped aluminosilicate fiber irradiated at $488 \mathrm{~nm}$. In Yb-doped aluminosilicate fiber, irradiation caused significant excess loss in the ultraviolet-visible spectrum, while the PDinduced loss of undoped aluminosilicate fiber can be ignored. In 2008, Engholm et al. [20] carried out PD experiments with Yb-doped silicate fiber samples. Very low-level PD was observed in $\mathrm{Yb}$-doped phosphosilicate fiber pumped by a $915 \mathrm{~nm}$ high-power diode. In 2008, Jetschke et al. [21] used Yb-doped fiber pumped by a $915 \mathrm{~nm}$ laser to study the change of PD with the concentration of co-dopant aluminum and phosphorus. Although high concentration co-doping was required, the core composition with equal aluminum and phosphorus content was the most promising to achieve YDF with low PD, high laser efficiency, and low laser core numerical aperture. In 2009, Leich et al. [22] reported the experiment of thermal treatment of photodarkened YDF samples. The non-isothermal bleaching method at different temperature ramp rates could be used to determine the thermal energy distribution of color centers. The average value of the distributed activation energy was about $1.3 \mathrm{eV}$ and the FWHM is $0.5 \mathrm{eV}$. In 2009, Söderlund et al. [23] studied thermal-bleaching (TB) of PD-induced loss in LMA Yb-doped silica fiber with $20 \mu \mathrm{m}$ core diameter. In 2009, Engholm et al. [24] showed that the PD resistivity of YDF lasers could be greatly improved by cerium co-doping. In 2009, Ponsoda et al. [25] proposed a method of TB for LMA Yb-doped fiber. The photodarkened YDF sample was recovered to original state by thermal annealing. Next year, Ponsoda et al. [26] examined the effect of PD-induced pump light absorption on YDF thermal loading. In these experiments, the fiber 
was cladding-pumped at $915 \mathrm{~nm}$, air-cooled by natural convection, and monitored with a mid-infrared thermal camera. It was found that fiber temperature was related to progressive PD. In 2010, Yoo et al. [27] reported the PD behavior of Yb-doped aluminosilicate fiber at high temperature. In 2010, Ye et al. [28] measured and analyzed the change of refractive index caused by PD and TB in YDF with high accuracy, based on a modal interference method. The influence of the PD-induced refractive index change (RIC) on fiber lasers was discussed. In 2011, Leich et al. [29] reported PD kinetics characterization of YDF samples in a wide range of temperatures from 77 to $773 \mathrm{~K}$ and with respect to different concentrations of $\mathrm{Yb}_{2} \mathrm{O}_{3}$. When the time went to infinity, the saturation loss was obviously depended on the fiber temperature. In 2011, Ponsoda et al. [30] examined the temperature dependence of PD in Yb-doped silica fibers. A series of continuous PD experiments were carried out on the same fiber samples. The results showed that it had good repeatability without an obvious change of glass structure. They found that in the process of infrared irradiation, the level of saturation of the PD losses could be determined by the core temperature. They observed that the change of core temperature, which was caused by pump absorption due to PD, would affect the inversion level and PD processes. In 2011, Mattson [15] observed a characteristic line at $2.6 \mathrm{eV}(477 \mathrm{~nm})$ for $\mathrm{Yb} / \mathrm{Al}$ and co-doped silica fibers. This linewas proposed to be due to inter-center excitation transfer from type II oxygen deficiency centers ODC(II) to $\mathrm{Tm}^{3+}$ trace impurities. In 2012, Gebavi et al. [31] examined the reduction of PD loss in $\mathrm{Yb}$-doped aluminosilicate fibers using light irradiation with a wavelength of $633 \mathrm{~nm}$. It was demonstrated that the final PB value depended on the irradiation intensity of bleaching light, but for the determined bleaching light intensity, the percentage of PD reduction was independent of the dopant concentration. In 2014, Riccardo Piccoli et al. [32] discussed the effect of visible light irradiation on PD in $1070 \mathrm{~nm}$ YDF laser. Simultaneous PD and PB effects caused by $976 \mathrm{~nm}$ and $405 \mathrm{~nm}$ or $550 \mathrm{~nm}$ radiations respectively were investigated. They observed a significant $\mathrm{PB}$ effect due to $405 \mathrm{~nm}$ radiation but it did not completely recover. A strong absorption of the $405 \mathrm{~nm}$ radiation by the excited ions (Excited-State Absorption) was also observed, which was found to be the main limiting factor of bleaching performance together, and PD losses caused by ground-state absorption were observed. In 2015, Zhao et al. [33] reported significant bleaching of Yb-doped fiber pumped at $793 \mathrm{~nm}$. Up to 68\% PD loss at $810 \mathrm{~nm}$ was bleached. The bleaching experiment under different powers showed that the pump power was positively correlated with the bleaching. In 2018, RÖPKE et al. [34] presented a microscopic model, which fully described the experimental experiences of PD research and was based on appropriate micro-optical mechanisms. The PD effect was regarded as a relaxation process of a statistical ensemble of micro-optical centers (PD complexes). These micro-optical centers (PD complexes) were reversibly converted into color centers by the energy of pump photons, resulting in the measurable PD loss. In 2019, Zhao et al. [35] reported the fundamental elimination of the PD effect in YDF by deuterium loading. No PD phenomenon was observed in TDF by deuterium pre-loading under $915 \mathrm{~nm}$ pumping conditions. In 2019, Zhao et al. [36] proposed a phase-separation method of nanoporous glass to prepare low PD YDF. Compared with the improved conventional vapor deposition method, equilibrium PD-induced excess loss of the nanoporous glass fiber was reduced to $35.07,12.49$, and $1.69 \mathrm{~dB} / \mathrm{m}$ at 702, 810, and $1041 \mathrm{~nm}$, respectively, despite higher $\mathrm{Yb}^{3+}$ concentration. In 2020, Cao et al. [37] found that in high-power YDF amplifiers, $\mathrm{H}_{2}$ loading could fundamentally inhibit the deterioration of the optical aging effect and laser performance.

\section{Mechanism of Photodarkening}

The PD effect is regarded as a relaxation process of a statistical ensemble of microoptical centers (PD complexes). These micro-optical centers (PD complexes) are reversibly converted into color centers by the energy of pump photons, resulting in measurable PD-induced excess loss [33]. The color centers lead to the increase of broadband absorption centered on the visible range. The color centers absorb the pump and the signal light, 
which reduces the power conversion efficiency of the fiber laser and can generate excess heat in the fiber laser $[38,39]$.

In some optical materials, the color center is produced by irradiation, which leads to excessive loss of broadband. In rare-doped laser materials, this effect is referred to as PD, which are inevitably exposed to intense pump radiation. The irradiation of the materials by the pump will directly or indirectly produce short band intrinsic absorption and produce electronic transitions of atoms or ions, i.e., the electrons in the valence band are excited to the conduction band, while holes are left in the valence band. After the electrons in the conduction band and holes in the valence band are trapped by the intrinsic defects and impurity defects of glass, the electron capture type color center (F Center) and the hole capture type color center (V Center) are formed respectively.

It is well known that high-energy radiation will produce an absorption band in a matrix such as silica glass $[40,41]$, and ultraviolet light is also used to make Bragg mirrors into fiber [42]. Therefore PD will appear in optical fiber, with ultraviolet laser [43], and even with an ultraviolet lamp $[20,44]$.

In the case of $\gamma$-ray, first, $\gamma$-ray interacts directly with optical fiber through the photoelectric effect, Compton scattering, and electron pair effect, which leads to the ionization of electron-hole pair in fiber; secondly, when the electron-hole pair is captured by the intrinsic defect, doping defect, impurity defect and radiation-induced defect in fiber, a special point defect with effective charge will be formed. This kind of defect can bind electrons and holes, cause the electrons or holes in the fiber to excite, and produce light absorption. Because its absorption band often falls in the visible light range, it is called the color center [45]. The oxygen-deficient center (ODC) in the germanium silicate glass has its characteristic absorption peak at $240 \mathrm{~nm}$, which releases free electrons when irradiated at resonance wavelength. The released electrons are trapped near the $\mathrm{GeO}_{4}$ tetrahedron, forming the $\mathrm{Ge}(\mathrm{I})$ color center and an absorption peak at $280 \mathrm{~nm}$. Its absorption range extends to the near-infrared band, showing PD [44].

There is a lot of evidence showing that the charge-transfer (CT) band appears in $\mathrm{Yb}$-doped aluminosilicate glass near $230 \mathrm{~nm}$. The transition of $\mathrm{Yb}^{3+}$ ion from trivalent state to low valence state leads to the formation of $\mathrm{Yb}^{2+}[3,20,46-50]$. When stable $\mathrm{Yb}^{2+}$ is formed, free holes are generated and excited to a higher energy level CT state, which leads to the formation of color center and the induced loss at ultraviolet and infrared wavelengths $[46,51,52]$.

It is found that in the $\mathrm{Yb} / \mathrm{Al}$ co-doped fiber working in the amplifier, the $\mathrm{PD}$ absorption spectrum becomes uniform with time, and the absorption loss at $477 \mathrm{~nm}$ and $558 \mathrm{~nm}$ increases with the extension of working time. These phenomena are considered to be caused by the transfer of inter-center excitation from type II oxygen deficiency centers (ODC (II)) to $\mathrm{Tm}^{3+}$ and $\mathrm{Er}^{3+}$ impurities, respectively. ODC (II) can cooperate with the valence electrons of $\mathrm{Yb}^{3+}$ ions to form color centers on the matrix, resulting in visible to near-infrared light [15].

In this section, we will focus on the conditions leading to defects (so-called PD) in the literature rather than the process of forming defects themselves. Generally speaking, glass can absorb X-ray and 200-220 nm ultraviolet light to produce a color center, which greatly reduces the transmission performance of glass [45]. However, recent research shows that the transmission performance of $\mathrm{Yb}$-doped fiber decreases significantly after irradiation at $488 \mathrm{~nm}[3,46,53], 793 \mathrm{~nm}[33], 915 \mathrm{~nm}[20,25,38,54], 920 \mathrm{~nm}[5], 977 \mathrm{~nm}[1,27], 980 \mathrm{~nm}$ [2] and thulium-doped fiber at $475 \mathrm{~nm}$ [8], $790 \mathrm{~nm}$ [13], $1064 \mathrm{~nm}$ [10,55], $1080 \mathrm{~nm}$ [14], $1120 \mathrm{~nm}$ [4], $1140 \mathrm{~nm}$ [11], $1175 \mathrm{~nm}$ [56]. We believe that under the condition of the laser working normally in the ordinary environment, the color center is produced by the interaction between high-energy (short-wavelength) photons and ions, atoms, or electrons in the crystal. This means that not all wavelengths (especially long wavelengths) leading to PD are directly involved in the process of generating color centers, and the conversion process from low-energy photons to high-energy photons needs to be carried out first. Furthermore, the ways of generating high-energy photons in the laser are different, mainly including 
excited-state absorption (ESA) [10], energy transfer upconversion (ETU) [13], avalanche upconversion [13], cooperative luminescence [57], and so on.

It is known that $\mathrm{Tm}^{3+}$ ions can easily up-convert infrared light to visible or ultraviolet light $[58,59]$, especially, when they are coupled with $\mathrm{Yb}^{3+}$ ions [60]. It is known that $\mathrm{Tm}$ ions with ${ }^{1} \mathrm{G}_{4}$ level show a strong absorption band at about $488 \mathrm{~nm}$ and Tm ions at ${ }^{1} \mathrm{G}_{4}$ level can be excited to ${ }^{1} \mathrm{I}_{6}{ }^{-3} \mathrm{P}_{0}$ level by ESA, so as to up-convert $488 \mathrm{~nm}$ radiation to its ultraviolet [61]. PD was observed in Tm-doped silica optical fibers pumped at $475 \mathrm{~nm}$ wavelength $[8,9]$.

With respect to the sample fiber test experiment mentioned above, ultraviolet and blue light are rarely used as the pump in the actual fiber laser, in fact, they are generated by the upconversion of the pump. Blue luminescence was observed in Tm-doped fiber pumped at 1.06-1.14 $\mu \mathrm{m}[4,10,11,14,55,56]$, as the three-photon-induced ${ }^{1} \mathrm{G}_{4}{ }^{-}{ }^{3} \mathrm{H}_{6}$ transition of $\mathrm{Tm}^{3+}$ (Figure 1). The same Tm ion continuously absorbs multiple photons to reach a higher excited-state energy level, thus emitting ultraviolet and blue light.

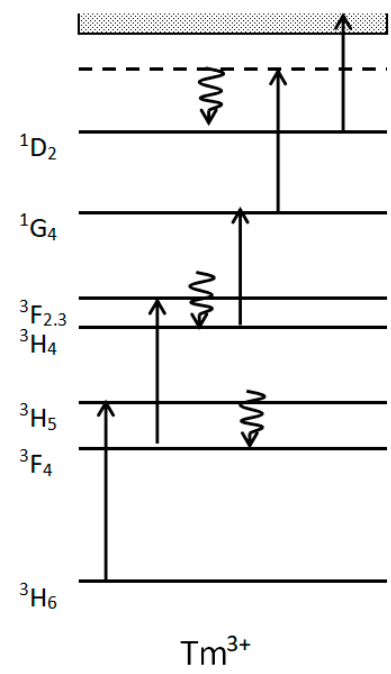

Figure 1. Partial energy level diagram of $\mathrm{Tm}^{3+}$. Straight arrows correspond to absorption at $1064 \mathrm{~nm}$, whereas wiggly arrows indicate nonradiative decay.

In 2010, G. Frith et al. [13] discussed the processes of generating blue light in $790 \mathrm{~nm}$ pumped Tm-doped fibers pumped and how fiber composition influenced these processes (Figure 2). Figure 2a shows the avalanche upconversion process. Tm ions absorb a photon with a wavelength of $790 \mathrm{~nm}$, transiting from ${ }^{3} \mathrm{H}_{6}$ to ${ }^{3} \mathrm{H}_{4}$, and then reach ${ }^{3} \mathrm{H}_{5}$ through a nonradiative transition. Next, the ions at the ${ }^{3} \mathrm{H}_{5}$ absorb a photon with a wavelength of $790 \mathrm{~nm}$ again, so as to enter a higher energy excited-state $\left({ }^{1} \mathrm{G}_{4}\right)$. Figure $2 \mathrm{~b}$ shows the energy transfer upconversion. Tm ions absorb a photon with a wavelength of $790 \mathrm{~nm}$, transiting from ${ }^{3} \mathrm{H}_{6}$ level to ${ }^{3} \mathrm{H}_{4}$ level. During the transition to ${ }^{3} \mathrm{H}_{5}$, the energy generated is transferred to another Tm ion excited to ${ }^{3} \mathrm{H}_{6}$, thus entering a higher energy excited-state $\left({ }^{1} \mathrm{G}_{4}\right)$.

These pieces of evidence clearly indicate that PD is related to the presence of $\mathrm{Tm}^{3+}$. In addition, some defects in fiber can also absorb pump power and generate blue photons [7]. When we pump TDF at $793 \mathrm{~nm}$, we also observe the peak spectrum at $470 \mathrm{~nm}$.

Compared with $\mathrm{Tm}^{3+}$ ions, $\mathrm{Yb}^{3+}$ ions have different energy level structures. Its energy level structure is simple, and there is no ESA and other phenomena [16]. Therefore, we cannot explain the phenomenon of PD in YDF pumped in the blue and infrared bands.

In 2007, Chávez et al. [1] showed that the phenomenon of PD was related to a multiexcitation of ytterbium clusters emitting light in the ultraviolet region. When using highpower pumping YDF with a wavelength of $977 \mathrm{~nm}$, clusters composed of three or four ytterbium ions can emit ultraviolet radiation. It was already demonstrated that the clustering of ytterbium emits light around $500 \mathrm{~nm}$ through cooperative luminescence from the simultaneous de-excitation of two clustered ions [61]. In 2007, Yoo et al. [3] found 
that YDF had an absorption peak near $220 \mathrm{~nm}$, which was related to $\mathrm{Yb}$. $\mathrm{Yb}$ ion was easy to capture oxygen holes around $\mathrm{Al}$ tetrahedron, but when $\mathrm{Yb}$ ion was too much, oxygen holes were insufficient, which would lead to the formation of $\mathrm{Yb}-\mathrm{Al}$ or $\mathrm{Yb}-\mathrm{Yb}$ dislocation chemical bond. Because the chemical bond of Ge-Ge and Ge-Si in germanosilicate glass was caused by oxygen defect, it was also considered to be oxygen defect here. When $488 \mathrm{~nm}$ light was used to irradiate, the absorption peak of ODCs was $220 \mathrm{~nm}$, which can produce two-photon absorption, then release free electrons, and be absorbed by $\mathrm{Yb}$ and $\mathrm{Al}$, forming the color center, leading to the phenomenon of PD. In 2012, Peretti et al. [62] showed that trace thulium existed in YDF. They thought that the reason for PD was that thulium ion produced ESA at $488 \mathrm{~nm}$ and produced ultraviolet light, reaching the charge-transfer absorption band at $230 \mathrm{~nm}$. The results showed that $\mathrm{Tm}^{3+}$ had a strong influence on the defect generation process in PD (Figure 3). The upconversion of Tm trace impurities in $\mathrm{Yb}$-doped pumped by near-infrared laser was an important reason for the generation of short-wavelength light $[63,64]$.
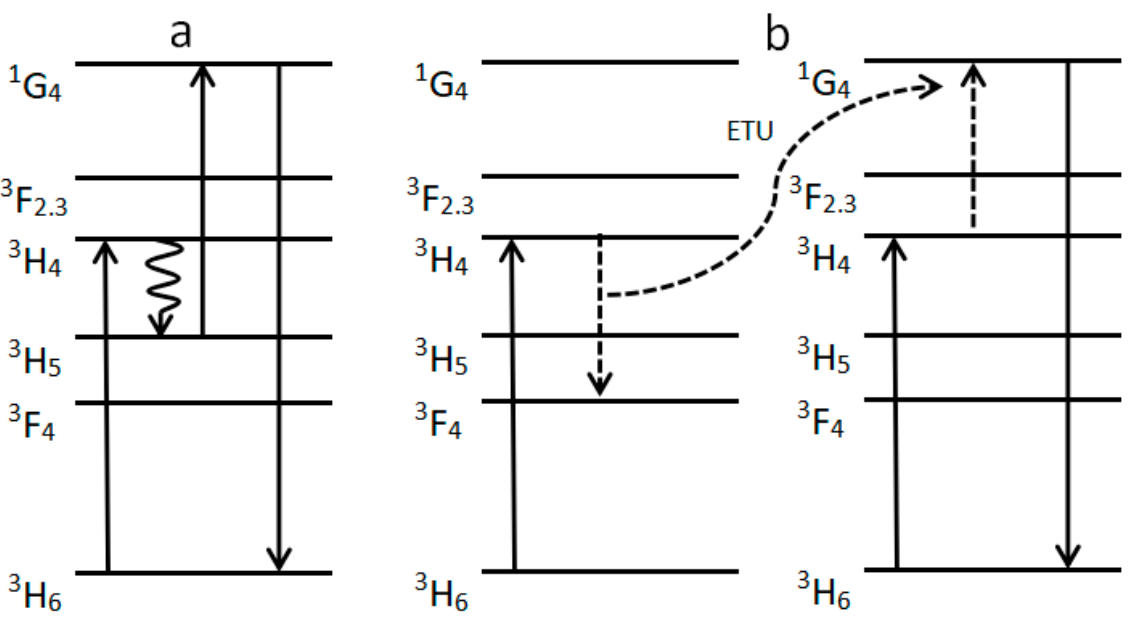

Figure 2. (a). possible photon avalanche upconversion process in Tm-doped silica. (b). proposed energy transfer upconversion process in Tm-doped silica.

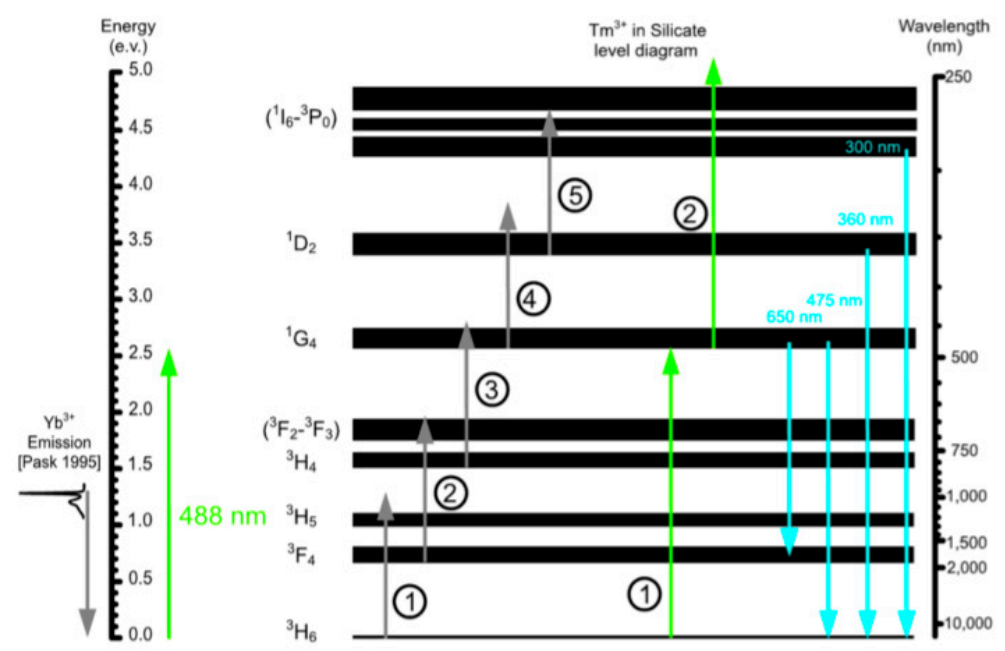

Figure 3. Schematic of conversion processes in $\mathrm{Yb} / \mathrm{Tm}$-doped fiber. Reproduced from [62], with the permission of AIP Publishing.

Cooperative luminescence, two-photon absorption, and Tm-doping can explain the PD of YDF in the blue and infrared band. In the process of inducing PD, these processes are not independent and need to work together [65]. 


\section{Phenomena and Problems Caused by Photodarkening}

The performance degradation of doped fiber is caused by PD. Thus, the stability of the output power and efficiency of doped fiber lasers and amplifiers is affected. The phenomena and problems caused by PD in doped fibers are mainly absorption spectrum change [1,2,4], output power reduction [2], temperature rise [38,39], mode instability threshold reduction [66-68], RIC [28], fluorescence lifetime reduction [32,69], etc.

\subsection{Change of Absorption Spectrum}

Laperle et al. [4] studied the absorption spectrum changes caused by PD of four different Tm-doped fibers exposed to a $1.12 \mu \mathrm{m}$ laser. The absorption spectrum changes caused by PD were mainly observed in the ultraviolet-visible part of the spectrum but extends slightly more than $1 \mu \mathrm{m}$ in the near-infrared (Figure 4). In 2007, A.D. D. Guzman Chávez et al. [1] reported the experimental results of PD and PB of Yb-doped silica fiber under $977 \mathrm{~nm}$ and $543 \mathrm{~nm}$ irradiation. The results showed that at $977 \mathrm{~nm}$, the absorption of the fiber increased in the broad spectrum (400-1000 nm), and the absorption coefficient decreases at the same time near $1 \mu \mathrm{m}$. In 2007, Manek-Hönninger et al. [2] studied the evolution of the PD effect with time in LMA Yb-doped silica fiber. When the fiber was exposed to pump light at about $980 \mathrm{~nm}$, the absorption spectrum showed an increase in the range of visible and near-infrared spectra (Figure 5).

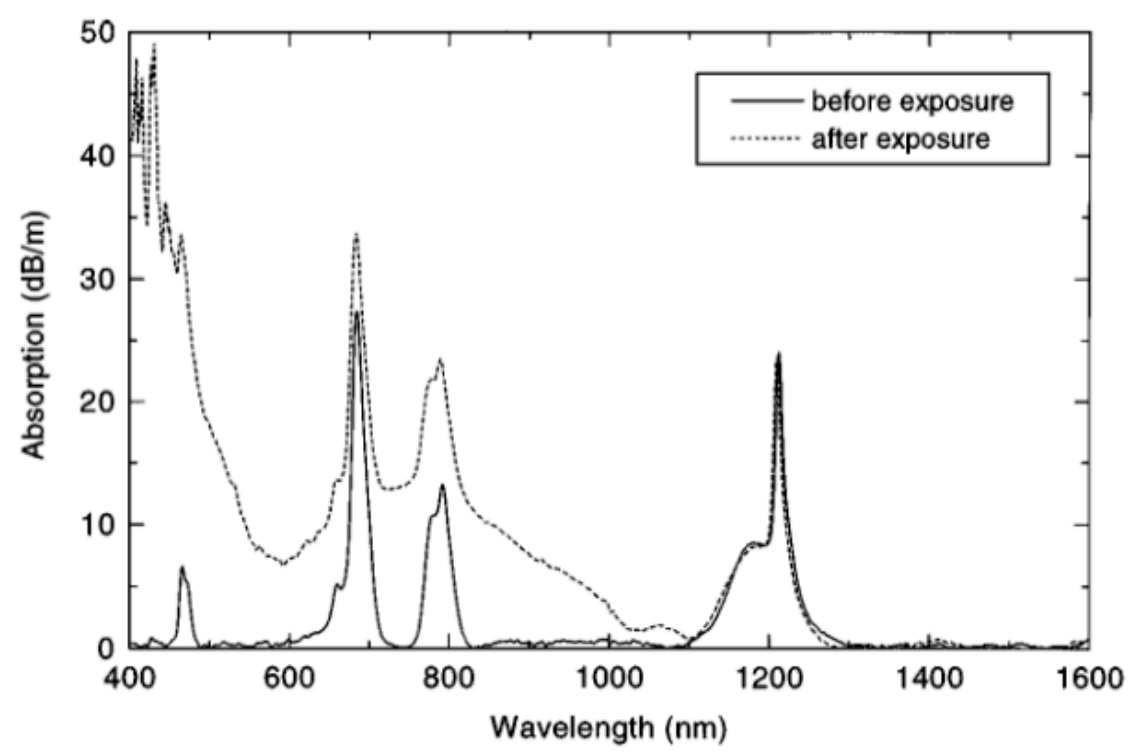

Figure 4. Absorption spectra of fiber $\mathrm{C}$ before and after exposure to $200 \mathrm{~mW}$ of power at $1.12 \mu \mathrm{m}$ for 120 s. Adapted with permission from [4] (c) The Optical Society.

As shown in Figures 4 and 5, at first glance it seems that the additional loss for Tmdoped fibers caused by PD is much higher than that for $\mathrm{Yb}$-doped fibers. We believe that there are two reasons why it is easier for Tm-doped fiber to generate PD than $\mathrm{Yb}$-doped fiber. First of all, the energy structure of the Tm ion is more prone to the upconversion phenomenon, which produces high-energy photons to excite color centers. Secondly, their experimental conditions are different. For example, The Tm-doped fiber is core-pumped and the $\mathrm{Yb}$-doped fiber is cladding-pumped in the above two experiments, which means that core-pumping can lead to higher pump energy densities for generating PD.

\subsection{Output Power Reduction}

Because the absorption spectrum of the color center generated in the PD process covers the pump band and even the signal band of the fiber laser, the output power and slope efficiency of the fiber laser is significantly reduced. In 2007, Manek-Hönninger et al. [2] measured the slope efficiency of a CW fiber laser oscillator by exposure to $45 \mathrm{~W}$ of pump 
power at $976 \mathrm{~nm}$ under different light aging conditions. The slope efficiency decreased considerably when a fiber with photon darkening was used as the laser medium (Figure 6).

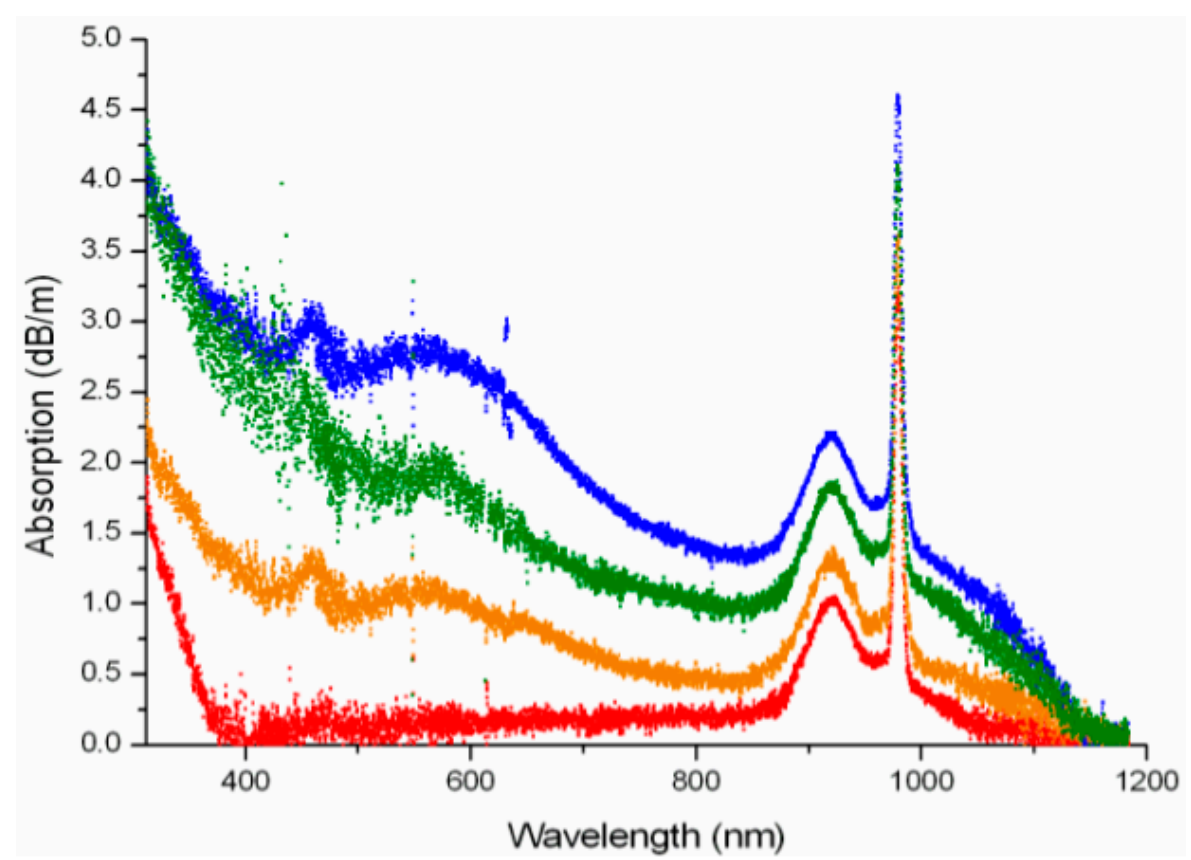

Figure 5. Absorption spectra of an unphotodarkened LMA Yb-doped fiber (red curves) and of the same fiber at different states of PD at $7 \mathrm{~min}, 15 \mathrm{~min}$, and $100 \mathrm{~min}$ (orange, green, and blue) of pumping the fiber by the light of $45 \mathrm{~W}$ at $976 \mathrm{~nm}$. Adapted with permission from [2] () The Optical Society.

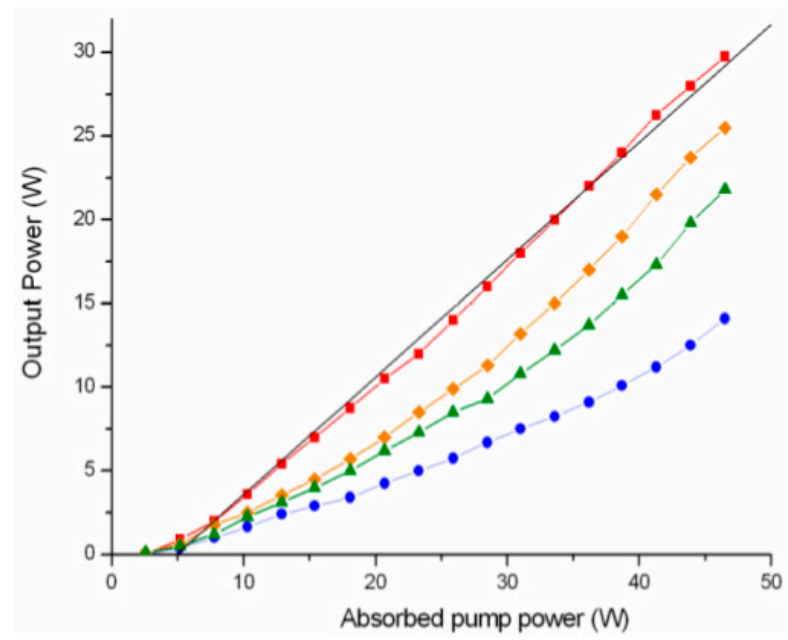

Figure 6. Output characteristics of the fiber laser for different states of PD: unphotodarkened fiber (red squares and linear fit to the data as a black solid line), $16 \mathrm{~min}$ (orange squares), 64 min (green triangles), and $155 \mathrm{~min}$ of PD (blue circles). Adapted with permission from [2] (c) The Optical Society.

On the other hand, the deactivation of doped ions in the process of color center generation also reduces the laser efficiency. In 2013, Jetschke et al. [70] studied the fluorescence characteristics of $\mathrm{Yb}$-doped fiber before and after pump irradiation. It was found that the fluorescence intensity and lifetime of $\mathrm{Yb}^{3+}$ decreased significantly during $\mathrm{PD}$, which was remarkably related to the measured PD loss. To explain this phenomenon, a theory of non-radiative energy transfer from excited $\mathrm{Yb}^{3+}$ ions to atomic defects (color centers) close to $\mathrm{Yb}^{3+}$ ions was proposed. This energy transfer leads to the inactivation of $\mathrm{Yb}^{3+}$ ions, resulting in additional loss of laser efficiency. 


\subsection{Temperature Increase}

$\mathrm{PD}$ results in the decrease of laser power, and the lost energy is eventually converted into the heat inside the fiber, which causes the temperature of the fiber to rise. In 2010, Ponsoda et al. [38] measured the temperature of Yb-doped LMA fiber during a PD experiment using a thermal camera. In these experiments, the fiber temperature was measured while PD experiments were performed using infrared radiation (i.e., $915 \mathrm{~nm}$ ). When the pump power was $5.7 \mathrm{~W}$ and $10.5 \mathrm{~W}$, the attenuation of the core absorption coefficient and the change of the fiber temperature during the pumping process of the probe signal with the wavelength of $600 \mathrm{~nm}$ were detected simultaneously. They observed that the temperature increased as the loss increased (Figure 7).

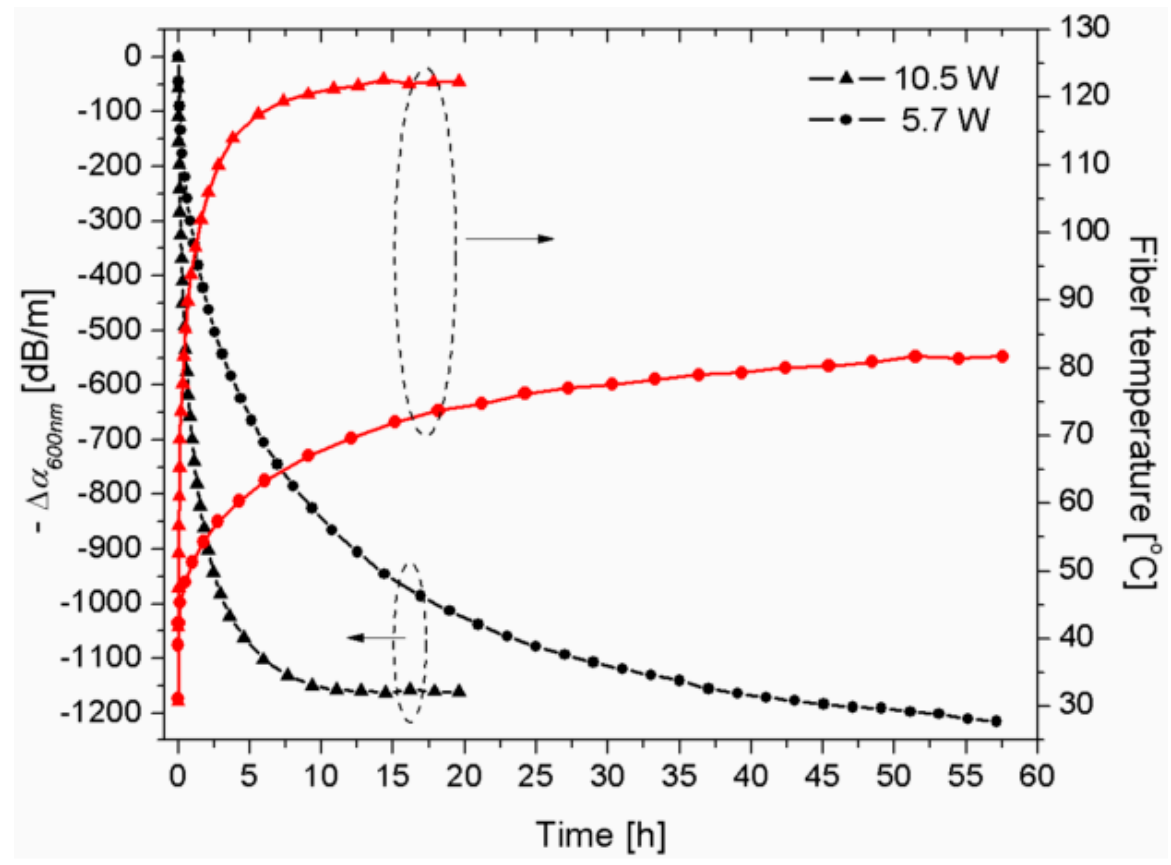

Figure 7. PD-induced absorption coefficient change $(\Delta \alpha)$ at $600 \mathrm{~nm}$ (primary $y$-axis) and respective fiber temperature (secondary $y$-axis) measured with a thermal camera. Adapted with permission from [38] () The Optical Society.

\subsection{Mode Instability Threshold Reduction}

Through systematic experiments and simulations, it is found that the thermal composition of PD is an important reason for the mode instability and beam quality degradation of high power fiber laser [66-68]. In 2015, Otto et al. [66] showed that PD would reduce the threshold of mode instability. It was considered that reducing PD was a promising way to reduce mode instability. The experimental results of PD and mode instability showed that even the negligible power loss caused by PD could reduce the mode instability threshold by two times. In 2016, Ward proposed a theory of quasi-static degradation caused by PD in the fiber amplifier. This creates a persistent absorption grating that remains phase-shifted from the modal interference pattern. This leads to power transfer from the fundamental mode to a higher-order mode, and the wavelength shift is very small. The whole process takes place on a time scale of minutes to hours. This process was modeled in LMA step-index and photonic crystal fibers and was found to produce reasonable threshold values [67].

\subsection{Refractive Index Change}

The phenomenon of PD leads to the RIC. The reason for the RIC is the structure change [71-82] and the generation of color center [83]. Experiments showed that when the photosensitive optical fiber was irradiated by ultraviolet light, the glass structure in some areas was more compact [71]. Studies performed on Tin-doped silica optical fibers proved that the RIC could be ascribed to structural rearrangements induced by photochemical 
reactions [72]. Different color centers have different photoconductivity characteristics, which will lead to the change of refractive index.

In 1990, Hand and Russell [53] used Kramers-Kronig relation to relate the variation of the refractive index of optical fiber with the spectral variation of optical fiber in ultraviolet absorption.

$$
\delta n(\omega)=\frac{c}{\sqrt{\pi}} \sum_{i} \frac{\delta \alpha_{i}\left(\omega_{i}\right) b_{i}}{\omega_{i}^{2}-\omega^{2}}
$$

where $\delta n(\omega)$ was the RIC when the angular frequency was $\omega, c$ was the speed of light in vacuum, $\delta \alpha_{i}$ was the absorption coefficient change, $\omega$ was the center frequency of the work and $\omega_{i}$ was the center frequency of each absorption peak. It indicated that any change in absorption at any wavelength introduced RIC at all wavelengths. Thus, the existence of RIC induced by PD and TB could be anticipated.

In 2010, Ye et al. [28] conducted high-precision measurement and analysis of RIC caused by light aging and TB in ytterbium-doped fiber based on the modal interference method. PD-induced RIC was positive at the ytterbium lasing wavelengths near $1080 \mathrm{~nm}$, and it approached a saturated level, which was in the order of $10^{-6} \sim 10^{-5}$ for the tested fiber samples.

\subsection{Fluorescence Lifetime Reduction}

In 2013, Jetschke et al. [70] found that the fluorescence intensity and lifetime of $\mathrm{Yb}^{3+}$ decreased significantly before and after the PD experiment, which was significantly related to the measured PD loss. In 2014, Piccoli et al. [32] studied the effect of PD on the fluorescence lifetime of $\mathrm{Yb}$ and found that the additional loss in equilibrium state caused by $\mathrm{PD}$ has a linear relationship with the reduction of $\mathrm{Yb}$ fluorescence lifetime. In the same year, Li et al. [69] measured the fluorescence power attenuation spectrum of darkened and nondarkened $\mathrm{Yb}$-doped fiber, and obtained that the fluorescence lifetime of the darkened fiber decreased by $12 \%$, while the fluorescence life was linearly related to the laser efficiency, consequently, the laser efficiency decreased by $12 \%$.

\section{Bleach of Photodarkened Fiber}

PD can be bleached under certain conditions. The process of PD is the competition between PD and bleach [65]. When the rate of PD is equal to that of bleach, the PD reaches saturation. Drift can be divided into PB and TB.

\subsection{Thermal-Bleaching}

Temperature is used to describe the degree of thermal movement of micro particles, which has a significant impact on the stability of the color center and is an important factor in the thermal annealing effect of the color center. It is generally believed that the higher the temperature, the more serious the annealing of the color center [22,84,85]. In 2009, Martin Leich et al. [21] studied TB of PD-induced loss in a $10 \mu \mathrm{m}$ core diameter, LMA Yb-doped silica fiber. Pristine and photodarkened samples are subjected to thermalization. With the increase of temperature, PD loss begins to recover at $\sim 350{ }^{\circ} \mathrm{C}$ and completely recovers when the temperature reached $\sim 625^{\circ} \mathrm{C}$. However, before recovery, the photodarkened fiber exhibits a further heat-induced increase of absorption loss. This phenomenon is attributed to the permanent increase of color centers and a temperature-dependent broadening of the absorption spectrum [23]. However, some studies have shown that the decrease of PD-induced loss in a specific band with the increase of temperature may be the result of the transition from one color center to another, not necessarily the annealing of the color center [86,87].

\subsection{Photobleaching}

At present, the PB wavelengths of ytterbium-doped fiber are $355 \mathrm{~nm}[1], 405 \mathrm{~nm}[32,88]$, $514 \mathrm{~nm}$ [46], $543 \mathrm{~nm}$ [1,89], $550 \mathrm{~nm}$ [88,90], $633 \mathrm{~nm}$ [1], $793 \mathrm{~nm}$ [33], and $810 \mathrm{~nm}$ [33]. However, only Laperle et al. used visible light to PB in Tm-doped fiber PB experiment [12]. 
In 1994, Atkins et al. [91] showed that when using $514 \mathrm{~nm}$ bleached Tb-doped fiber, the reason is that the two-photon excitation can release electrons from the color center and make the color center disappear. In 2014, Piccoli et al. [32] used Yb-doped fiber photondarkened by $405 \mathrm{~nm}$ light radiation, and they observed the partially recovered $\mathrm{PB}$ phenomenon. They showed that the reason for the incomplete PB phenomenon is the strong absorption of $405 \mathrm{~nm}$ radiation by excited ions (excited-state absorption), and PD loss caused by ground-state absorption is also observed.

In some cases, PB can also cause the same high temperature as TB to bleach the color center. In the study of Tm-doped fibers, Millar et al. [8] speculated that the bleaching phenomenon in some PB experiments was essentially caused by high temperature rather than photon irradiation, and they found that bleaching began when the fiber was heated to $350{ }^{\circ} \mathrm{C}$. In the theoretical simulation, the core could reach a similar temperature by irradiating the laser with the same wavelength and power.

\section{Experimental Setup of Photodarkening}

\subsection{Additional Loss Measuring Device at Characteristic Wavelengths}

The characteristic wavelength loss measuring device is to measure the loss of probe light with a specific wavelength in the process of PD. By coupling the pump light and probe light into the sample fiber at the same time, the change of probe light with time is recorded by a power meter. Because the pump light and probe light are mixed together, it is necessary to use a filter to extract the probe light $[4,7,17,20,54]$. To minimize the influence of probe light on the sample fiber, the probe light power needs to be far less than the pump light power. Consequently, it is not enough to extract probe light only by the filter, and the noise produced by the pump and ASE will disturb the measurement. Therefore, a combined PD and TB measurement of an LMA Yb-doped fiber is presented by Ponsoda et al. (Figure 8) [25].

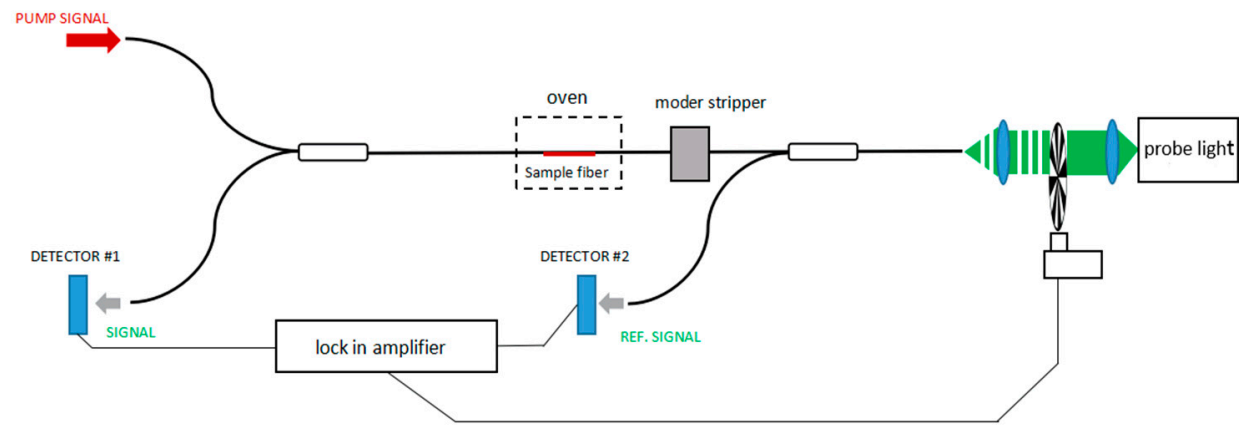

Figure 8. Experimental setup for measuring both PD rate and TB.

The device introduces a lock-in amplifier to extract probe light. To ensure the same degree of PD in the sample fiber and provide convenience for temperature control, the sample fiber needs to be short enough. Interestingly, PD has been shown a reversible process by applying thermal treatment [50,92] or ultraviolet irradiation [2] to the Yb-doped fiber. Therefore, it is possible to repeat the experiment without replacing the optical fiber sample. This device is most commonly used in PD experiment [14,22,25,28,30,33,37,73]. It cannot only measure the characteristic wavelength absorption, but also can be used in absorption spectrum measurement and refractive index measurement.

\subsection{Absorption Spectrum Measuring Device}

The absorption spectrum measuring device is for measuring the transmission spectrum before and after the sample fiber PD experiment, and subtracting the two spectra to obtain the PD absorption spectrum. Because it is not necessary to measure when the pump is working, the noise caused by the pump does not need to be considered, so the whole device is relatively simple $[15,17]$. The absorption spectrum could also be measured by changing the device in the previous section [22]. 


\subsection{Refractive Index Measuring Device}

The RIC induced by PD and bleaching is relatively small. Therefore, interferometric methods must be used to obtain sufficient resolution. Therefore, the mainstream device for measuring RIC in PD experiment is based on the modal interference method and the absorption spectrum measurement device [28]. The core fusion is intentionally offset, which is approximately equal to the core radius of the YDF, as shown in Figure 9.

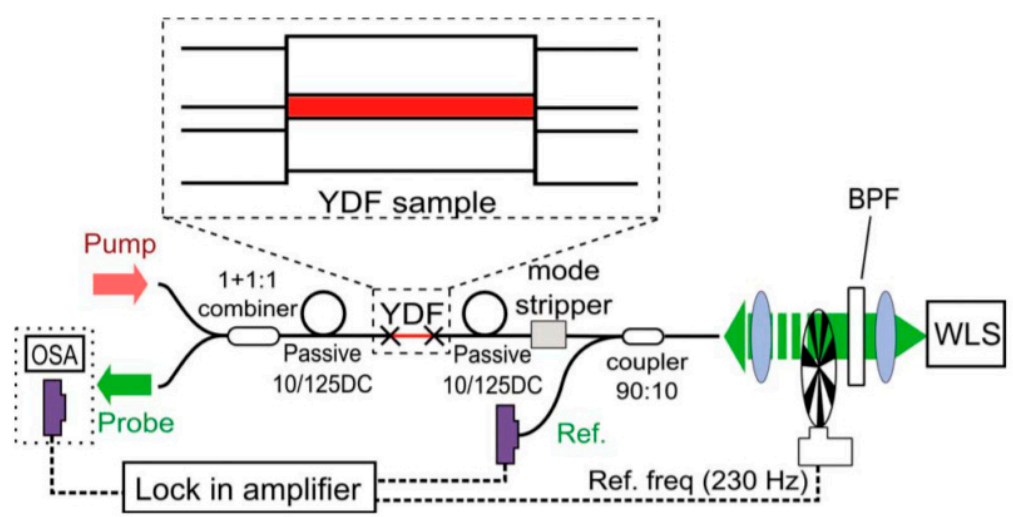

Figure 9. Experimental setup for RIC measurement. YDF, Yb-doped fiber; BPF, bandpass filter; WLS, white light source; OSA, optical spectrum analyzer. Adapted with permission from [28] @ The Optical Society.

At the first splice, both $\mathrm{LP}_{01}$ and $\mathrm{LP}_{11}$ modes are excited in the YDF sample. As the probe light propagates along the YDF, the phase difference occurs between the two transverse modes due to the different propagation constants of the two transverse modes. Interference occurs when the light is coupled back to the single-mode fiber at the second splice, when a white light source (spectral range from $400 \mathrm{~nm}$ to $1400 \mathrm{~nm}$ ) is used as the detection light, periodic oscillation of the transmission spectrum is caused. The spectrum with a wavelength between 1050-1100 nm is as shown in Figure 10.

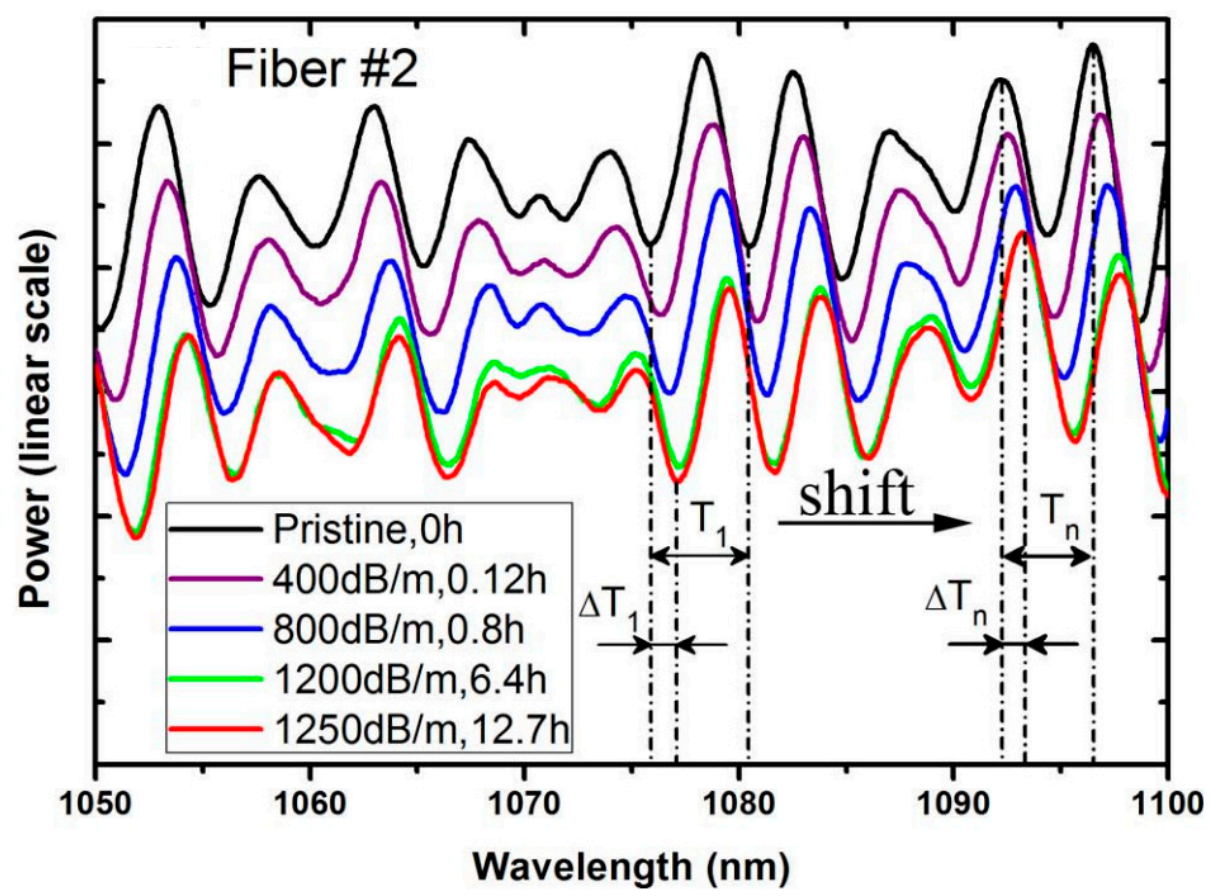

Figure 10. Observed phase shift in the modal interference fringes at various PD loss levels and corresponding times. Adapted with permission from [28] @ The Optical Society. 


$$
\Delta n_{\mathrm{PD}}=\frac{\lambda}{2 \pi l\left(\eta_{1}-\eta_{2}\right)} \Delta \phi
$$

The phase shift of the modal interference fringe can be calculated by $\Delta \phi=2 \pi \Delta T / T$. The change of refractive index can be obtained by introducing $\Delta \phi$ into formula PD. Where $\eta_{i}(\mathrm{i}=1,2)$ are fractions of power in the core for the $\mathrm{LP}_{01}$ and $\mathrm{LP}_{11}$ modes. The fractions are calculated from the mode field distribution by numerically solving the fiber characteristic equation. For both fibers used in the experiment, $\eta_{1} \sim 0.78$ and $\eta_{2} \sim 0.1$ in the spectral range near $1080 \mathrm{~nm}$.

\section{Theoretical Study}

The theoretical formula can be a useful tool to study the phenomenon of PD, the most widely used formula is the classical tensile exponential function, which makes the data fit. The formula is as follows $[12,25,29,33-35,50,67,93-95]$.

$$
\alpha_{\mathrm{PD}}(t)=\alpha_{\max }\left[1-\exp \left(-(t / \tau)^{\beta}\right)\right]
$$

where $\alpha_{\mathrm{PD}}(t)$ represents the loss induced at a time $t$ after the pump is switched on, $\alpha \mathrm{max}$ the loss at the final equilibrium state, $\tau^{-1}$ is the time scale, and $\beta$ is a parameter that ranges between 0 and 1 and is referred to as the stretching parameter. This equation is the most commonly used empirical formula, which can describe the relaxation rates of many physical properties of complex systems such as polymers and glasses, and the fitting result is the same as the exponential attenuation distribution of the experimental results. The time constant $\tau^{-1}$ is determined as a benchmarking method for PD rate comparison.

Ponsoda et al. [25] used a double exponential function to fit the equation as follows.

$$
-\Delta \alpha(\mathrm{t})=\alpha_{0}+\alpha_{1} \cdot \exp \left(-t / \tau_{1}\right)+\alpha_{2} \cdot \exp \left(-t / \tau_{2}\right)
$$

The constants $\alpha_{0}$ are saturation parameters; $\alpha_{1}$ and $\alpha_{2}$ are amplitude constants; $\tau_{1}$ and $\tau_{2}$ are $\mathrm{PD}$ time constants of fast exponential decay and slow exponential decay, respectively.

The normalized probe transmission intensities could be fitted with a stretchedexponential function of the form $[3,7,18,27]$

$$
T(t)=A \cdot \exp \left[-(t / \tau)^{\beta}\right]+(1-A)
$$

where $T$ is the normalized transmission, $(1-A)$ is a steady-state transmission of a fit, $\tau$ is a characteristic time constant for a fit, and $\beta$ is a dispersive parameter in a range between 0 and 1 . The fitting of the curves was done using the least square method.

Martin Leich et al. $[29,94]$ described the conversion of the PD precursor $A$ to the color center $B$ by optical pumping. The transition from a precursor $A$ to a chromocentric $B$ is described by reversible first-order reaction at the micro-level. Based on the experimental phenomena of TB, they also described the non-absorbent state $C$ as the intermediate state of TB.

$$
A \stackrel{k_{+}}{\longleftrightarrow} B \stackrel{k_{T}}{\longrightarrow} C \stackrel{k_{R}}{\longrightarrow} A
$$

with the transition rates $k_{+}$and $k_{-}$of excitation and de-excitation of color centers, respectively. $k_{T}$ is the TB rate and $k_{R}$ is the recovery rate. Rate constant $\tau^{-1}=k_{-}+k_{+}+k_{T}+k_{R}$

From the reactions (6), it is assumed that $C_{A}(t)+C_{B}(t)+C_{C}(t) \equiv C_{A}(0)+C_{B}(0)+$ $C_{C}(0)$ is a constant, hence, the whole process can be described by the following two linear rate equations

$$
\begin{gathered}
\frac{d C_{A}}{d t}=k_{R} C_{A 0}-\left(k_{+}+k_{R}\right) C_{A}+\left(k_{-}-k_{R}\right) C_{B} \\
\frac{d C_{B}}{d t}=k_{+} C_{A}-\left(k_{-}+k_{T}\right) C_{B}
\end{gathered}
$$


$C_{A}, C_{B}$, and $C_{C}$ are the densities of precursor $A$, color center $B$, and nonabsorbable State $C$, respectively. With the special initial conditions $C_{A}(0)=C_{A 0}$ and $C_{B}(0)=C_{C}(0)=0$, the explicit solution for the density of color centers normalized to the initial density of precursors is

$$
\frac{C_{B}(t)}{C_{A 0}}=\frac{k_{+}}{2 G W}\left[Z\left(e^{-\beta t}-e^{-\alpha t}\right)+k_{R} W\left(2-\left(e^{-\beta t}+e^{-\alpha t}\right)\right)\right]
$$

with the abbreviations $G=k_{R}\left(k_{-}+k_{T}+k_{+}\right)+k_{+} k_{T}, Z=k_{R}\left(k_{-}+k_{T}+k_{+}\right)+2 k_{+} k_{T}+k_{R^{\prime}}^{2}$ $W=\sqrt{S^{2}-4 G}, S=k_{-}+k_{+}+k_{R}, \alpha=(S+W) / 2$ and $\beta=(S-W) / 2$.

The quantity $C_{B}(t) / C_{A 0}$ is considered to be proportional to the PD loss. According to Formula (9), the first term in square brackets describes the rapid rise (with $\alpha$ ) of PD loss after the pump is turned on and slow decline (with $\beta$ ) after passing the maximum. The second term describes the conversion of intermediate state $C$ to precursor $A$. When $t$ tends to infinity, the real equilibrium value $\left(d C_{B} / d t=0\right)$ will be achieved and depends on the discussed transition rates only,

$$
\frac{C_{B}^{e q}}{C_{A 0}}=\frac{k_{+} k_{R}}{k_{R}\left(k_{-}+k_{T}+k_{+}\right)+k_{+} k_{T}}
$$

According to Formula (10), when $k_{R}=0$, all color centers would vanish after longtime pumping.

Röpke [34] showed that the color centers were generated by irradiation of different wavelengths, but they could also be eliminated by optical or thermal treatment. PD irradiated by a single pump was also a process of simultaneous generation and annihilation of color centers, resulting in a balanced loss of $\alpha_{e q}$ after a long time constant power pump. They proposed that the probability of a complex-forming a color center was $p$. The measurable PD loss was caused by the absorption of these color centers. The temporal development of this loss was determined by the statistical distribution of the transition rates and the pump power $(P)$. Furthermore, the PD effect during pump light irradiation was understood as a reversible process of activation (creation) and deactivation (destruction) of color centers. Therefore, we use the activation (formation) rate $k_{+}(s, P) \geq 0$, the deactivation (erasure) rate $k_{-}(s, P) \geq 0$, and the master equation $\delta p / \delta t=k_{+}(1-p)-k_{-} p$ to determine the temporal evolution of the PD state in a relaxation process. This results in [34]

$$
\begin{gathered}
p(t, s, P)=p_{e q}+\left\{p_{0}(s)-p_{e q}\right\} e^{-\kappa(s, P) t} \\
p_{e q}=\frac{k_{+}(s, P)}{k_{+}(s, P)+k_{-}(s, P)} \\
\kappa(s, P)=k_{+}(s, P)+k_{-}(s, P)
\end{gathered}
$$

Here $0 \leq p_{0}(s) \leq 1$ is the initial state at $t=0 . \kappa(s, P)$ is the relaxation (transition) rate, depending on the "speed" parameter $s$ and the pump power $P$. The final state, $p_{e q}=p(t \rightarrow \infty$, $s, P)$, is the attractor of the relaxation process. It represents the balance of the activation and deactivation processes. This result allows $p_{e q}$ depending on both $s$ and $P$.

Laperle et al. [96] proposed a formula to describe the time-dependent power loss along the fiber caused by competing PD and PB processes.

$$
\frac{d p_{s}(t)}{d z}=-\left(\alpha_{s}+\alpha_{E}(z, t)\right) P_{S}
$$

where $\alpha_{S}$ and $\alpha_{E}$ are intrinsic absorption and additional absorption, $P_{S}$ is the signal power distribution along the fiber, $t$ is time, and $Z$ is the ordinate in the optical fiber. This formula describes the influence of intrinsic absorption $\alpha_{S}$ and additional absorption $\alpha_{\mathrm{E}}$ caused 
by PD on the propagation power in the fiber. time-dependent excess loss coefficient is written as

$$
\alpha_{\mathrm{E}}(z, t)=\int_{0}^{2 \pi} \int_{0}^{a} \sigma_{C} N_{C}(r, \phi, z, t) \psi_{s}(r, \phi) r d r d \phi
$$

where $\sigma_{c}$ is the absorption cross-section of the color center at the signal wavelength, $N_{c}$ is the color center density, $\psi_{s}$ is the normalized signal profile, and $\alpha$ is the core radius. In 2003, he proposed a formula to describe the change of color center density when PD and PB were carried out simultaneously using the form of the stretch index with a time-dependent rate coefficient [97].

$$
\frac{d N_{C}}{d t}=\beta t^{\beta-1} v_{d}^{\beta}\left(N_{C, \max }-N_{C}\right)-\kappa t^{\kappa-1} v_{b}^{\kappa} N_{C}
$$

where $\beta$ and $\kappa$ are respectively the dispersion parameters for $\mathrm{PD}$ and $\mathrm{PB}, v_{d}$ and $v_{b}$ are the $\mathrm{PD}$ and $\mathrm{PB}$ rate coefficients, and $N_{C, \max }$ is the maximum color center density.

\section{Suppression Method of Photodarkening}

Because of the PD effect, the output power of the fiber laser and amplifier decreases continuously and the attenuation is large, which leads to the lack of stability and short operating lifetime of the system, which needs regular maintenance. This greatly restricts the application requirements of the system, limits the application scope and application field of the system. Therefore, the suppression of PD is particularly important.

\subsection{Changing the Pump Wavelength}

Some phenomena show that PD is related to the upconversion phenomenon, which can be suppressed by suppressing up conversion phenomenon. Taking Tm-doped fiber as an example, the phenomenon of PD was observed at the pump wavelength of 1.06-1.14 $\mu \mathrm{m}[4,10,11,14,55,56]$, but some studies show that in Tm-doped fiber, the phenomenon of PD has not been found at the pump wavelength of 1.25-1.6 $\mu \mathrm{m}$ [11]. If we avoid the wavelength that may cause up conversion phenomenon, we may avoid the phenomenon of PD, but it is impossible to change the wavelength at will in the construction of light laser, so the method of changing the wavelength is very limited.

\subsection{The Capture of Electrons and Holes Involved in the Generation of Defect}

Engholm et al. [24,98,99] compared and tested the additional loss of $\mathrm{PD}$ of $\mathrm{Yb} / \mathrm{Al}$ and $\mathrm{Yb} / \mathrm{Al} / \mathrm{Ce}$ fiber by co-doped $\mathrm{Yb}$-doped fiber with cerium $\left(\mathrm{Ce}^{3+} / \mathrm{Ce}^{4+}\right)$. The additional losses of $\mathrm{PD}$ of $\mathrm{Yb} / \mathrm{Al}$ and $\mathrm{Yb} / \mathrm{Al} / \mathrm{Ce}$ fiber were compared and tested. It was found that the introduction of cerium ions could improve the anti-PD performance of $\mathrm{Yb}$-doped fiber. As shown in Section 2, the interaction between high-energy photons and matrix leads to the ionization of electron-hole pairs in optical fibers; Secondly, when electron-hole pairs are captured by defects in optical fibers, color centers will be formed. The two valence states of cerium ions in the co-doped cerium ion fiber can capture electrons or holes involved in defect generation and convert them into another valence state, thus inhibiting the formation of color center, then the PD effect is reduced. $\mathrm{Ce}^{4+}$ is widely used as a decolorizer in the glass industry due to its strong oxidation, so it can reduce the generation of defects [100]. The researchers reported that the PD loss of $\mathrm{Yb}^{3+}$-doped fiber co-doped with cerium will be significantly reduced. In this case, because the energy levels of $\mathrm{Ce}^{3+}$ and $\mathrm{Ce}^{4+}$ are far from those of $\mathrm{Yb}^{3+}$, this energy transfer will not have a great impact on the laser itself.

\subsection{Avoid Clusters}

We showed that the phenomenon of PD was related to a multi-excitation of $\mathrm{Yb}$ clusters emitting light in the ultraviolet region [92]. It has been reported that fibers containing $\mathrm{Yb}$ clusters or $\mathrm{Yb}$ pairs are subject to enhanced light aging, while the high concentration of Al helps to reduce PD $[73,101]$. Al co-doping can adjust the distribution of ytterbium ions and effectively avoid the cluster of ytterbium ions [102]. Other studies have shown that 
phosphorus can also induce a cage around a part of the rare earths, so as to avoid rare-earth ion clusters [103]. Some evidence shows that co-doping phosphorus in Yb-doped fiber can avoid clusters more effectively than co-doping Al $[63,104]$.

\subsection{Add Deexcitation Channel}

The results show that co-doping a $\mathrm{Yb}$-doped fiber with $\mathrm{Er}^{3+}$ can significantly reduce the additional loss caused by PD [6,105]. Jetschke et al. [106] tested the additional loss of $\mathrm{Yb} / \mathrm{Al}$ and $\mathrm{Yb} / \mathrm{Al} / \mathrm{Er}$ fiber respectively. It was found that the additional loss of $\mathrm{Yb} / \mathrm{Al} / \mathrm{Er}$ fiber was significantly reduced, and its fluorescence intensity in the visible band was relatively weak. They thought that this was because a small amount of $\mathrm{Tm}^{3+}$ ion in $\mathrm{Yb}^{3+}$ cluster or $\mathrm{Yb}^{3+}$ ion carried out energy transfer with $\mathrm{Er}^{3+}$ in $\mathrm{Yb} / \mathrm{Er}$ fiber, while $\mathrm{Er}^{3+}$ did not have effective up conversion and excited-state absorption. Electrons in the high-energy state jump to the ground state with non-radiation, reducing the ultraviolet radiation, thus inhibiting the PD effect. Other Co-doped ions such as $\mathrm{Tb}^{3+}, \mathrm{Eu}^{3+}$, and $\mathrm{Nd}^{3+}$ can also increase the de-excitation channel, but the additional doping of other ions requires careful analysis of the laser characteristics of the fiber to ensure that other properties of $\mathrm{Yb}$-doped fiber laser will not be lost.

\subsection{Eliminate the Related Defects}

In $\mathrm{Yb}$-doped aluminosilicate fibers, the nonbridging oxygen hole centers (NBOHC) and the aluminum oxygen hole centers (AlOHCs) were considered to be important defects for causing PD [107,108]. By eliminating these defects, the PD effect can be reduced. In a high-power YDF amplifier, $\mathrm{H}_{2}$ load can fundamentally suppress the PD effect and greatly improve laser performance [14,37]. The reaction formula is as follows

$$
\mathrm{Si}-\mathrm{O} \cdots \mathrm{O}-\mathrm{Si}+\mathrm{H}_{2} \rightarrow 2 \mathrm{Si}-\mathrm{OH}
$$

Although the matrix structure of quartz glass is compact, $\mathrm{H}_{2}$ molecules move freely in quartz fiber. They can react with the dangling bonds of NBOHC to form a more stable covalent bond of $-\mathrm{OH}$ which is stable and transparent from the ultraviolet to the visible band. Furthermore, this reaction can release electrons that could be bound with the holerelated defects, so as to eliminate the related defects $[109,110]$.

\section{Summary}

This paper summarizes the generation, phenomenon, bleach, experimental device, theoretical research, and suppression methods of PD, in order to provide a reference for relevant research. To sum up, PD is an important factor affecting the power enhancement of fiber lasers. To reduce the influence of the PD on the fiber laser, it is very important to study the PD mechanism of fiber laser, which puts forward high requirements for the manufacturing technology of fiber. We believe that the main reason for PD is that the absorption spectrum of the color center in the fiber covers the pump or signal band, while the color center in the laser is due to the interaction between high-energy photons and ions, atoms, or electrons in the crystal, and the ways of high-energy photons produced by different doped fibers are verified. The color centers produced by high-energy photon excitation are also different. In particular, the specific processes of color center formation, transformation, and bleaching are very complex. Different doped ions and different concentrations will have a great impact on the color center. There is still a lot of work needed to study the color center in optical fiber further.

Author Contributions: Conceptualization, Y.Z. (Yi Zheng) and T.S.; investigation, T.S., X.S., Y.Z. (Yunhong Zhang) and H.Z.; writing-original draft preparation, T.S. and X.S.; writing-review, and editing, X.S. and T.S.; visualization, T.S.; Supervision, X.S. and Y.Z. (Yi Zheng). All authors have read and agreed to the published version of the manuscript. 
Funding: This work was supported by grants from the National Natural Science Foundation of China $(61735005,61925010)$, Natural Science Foundation of Beijing Municipality $(4182054,4212052)$, and Fundamental Research Funds for the Central Universities (2021RC206).

Institutional Review Board Statement: Not applicable.

Informed Consent Statement: Not applicable.

Conflicts of Interest: The authors declare no conflict of interest.

\section{References}

1. Chávez, A.D.G.; Kir'yanov, A.V.; Barmenkov, Y.O.; Il'ichev, N.N. Reversible photo-darkening and resonant photo-bleaching of Ytterbium-doped silica fiber at in-core 977-nm and 543-nm irradiation. Laser Phys. Lett. 2007, 4, 734-739. [CrossRef]

2. Manek-Hoenninger, I.; Boullet, J.; Cardinal, T.; Guillen, F.; Ermeneux, S.; Podgorski, M.; Doua, R.B.; Salin, F. Photodarkening and photobleaching of an ytterbium-doped silica double-clad LMA fiber. Opt. Express 2007, 15, 1606-1611. [CrossRef]

3. Yoo, S.; Basu, C.; Boyland, A.J.; Sones, C.; Nilsson, J.; Sahu, J.K.; Payne, D. Photodarkening in Yb-doped aluminosilicate fibers induced by $488 \mathrm{~nm}$ irradiation. Opt. Lett. 2007, 32, 1626-1628. [CrossRef]

4. Laperle, P.; Chandonnet, A.; Vallee, R. Photoinduced absorption in thulium-doped ZBLAN fibers. Opt. Lett. 1995, 20, 2484-2486. [CrossRef]

5. Koponen, J.J.; Söderlund, M.; Hoffman, H.J.; Tammela, S.K.J.O.E. Measuring photodarkening from single-mode ytterbium doped silica fibers. Opt. Express 2006, 14, 11539. [CrossRef] [PubMed]

6. Harter, D.J.; Morasse, B.; Tünnermann, A.; Chatigny, S.; Gagnon, É.; Broeng, J.; Iii, C.H.; Hovington, C.; Martin, J.P.; de Sandro, J.P. Low photodarkening single cladding ytterbium fibre amplifier. In Fiber Lasers IV: Technology, Systems, and Applications; International Society for Optics and Photonics: San Jose, CA, USA, 2007.

7. Koponen, J.; Soederlund, M.; Hofftnan, H.J.; Kliner, D.; Koplow, J. Photodarkening Measurements in Large-Mode-Area Fibers. Proc. SPIE 2007, 6453, 64531E. [CrossRef]

8. Millar, C.A.; Mallinson, S.R.; Ainslie, B.J.; Craig, S.P. Photochromic behavior of thulium-doped silica optical fibers. Electron. Lett. 1988, 24, 590-591. [CrossRef]

9. Brocklesby, W.S.; Mathieu, A.; Brown, R.S.; Lincoln, J.R. Defect production in silica fibers doped with TM ${ }^{3+}$. Opt. Lett. 1993, 18, 2105-2107. [CrossRef] [PubMed]

10. Broer, M.M.; Krol, D.M.; Digiovanni, D.J. Highly nonlinear near-resonant photodarkening in a thulium-doped aluminosilicate glass-fiber. Opt. Lett. 1993, 18, 799-801. [CrossRef]

11. Barber, P.R.; Paschotta, R.; Tropper, A.C.; Hanna, D.C. Infrared-induced photodarkening in tm-doped fluoride fibers. Opt. Lett. 1995, 20, 2195-2197. [CrossRef]

12. Laperle, P.; Chandonnet, A.; Vallee, R. Photobleaching of thulium-doped ZBLAN fibers with visible light. Opt. Lett. 1997, 22, 178-180. [CrossRef]

13. Frith, G.; Carter, A.; Samson, B.; Faroni, J.; Farley, K.; Tankala, K.; Town, G.E. Mitigation of photodegradation in 790 nm-pumped Tm-doped fibers. Proc. SPIE 2010, 7580, 75800A. [CrossRef]

14. Liu, Y.-Z.; Xing, Y.-B.; Lin, X.-F.; Chen, G.; Shi, C.-J.; Peng, J.-G.; Li, H.-Q.; Dai, N.-L.; Li, J.-Y. Bleaching of photodarkening in Tm-doped silica fiber with deuterium loading. Opt. Lett. 2020, 45, 2534-2537. [CrossRef]

15. Mattsson, K.E. Photo darkening of rare earth doped silica. Opt. Express 2011, 19, 19797-19812. [CrossRef] [PubMed]

16. Liang, Y.-J.; Liu, F.; Chen, Y.-F.; Wang, X.-J.; Sun, K.-N.; Pan, Z. New function of the $\mathrm{Yb}^{3+}$ ion as an efficient emitter of persistent luminescence in the short-wave infrared. Light-Sci. Appl. 2016, 5, e16124. [CrossRef] [PubMed]

17. Paschotta, R.; Nilsson, J.; Barber, P.R.; Caplen, J.E.; Tropper, A.C.; Hanna, D.C. Lifetime quenching in Yb-doped fibres. Opt. Commun. 1997, 136, 375-378. [CrossRef]

18. Koponen, J.J.; Söderlund, M.; Tammela, S.; Po, H.J.P.S. Photodarkening in ytterbium-doped silica fibers. Proc. SPIE 2005, $5990,599008$.

19. Jetschke, S.; Unger, S.; Roepke, U.; Kirchhof, J. Photodarkening in Yb doped fibers: Experimental evidence of equilibrium states depending on the pump power. Opt. Express 2007, 15, 14838-14843. [CrossRef] [PubMed]

20. Engholm, M.; Norin, L. Preventing photodarkening in ytterbium-doped high power fiber lasers; correlation to the UVtransparency of the core glass. Opt. Express 2008, 16, 1260-1268. [CrossRef]

21. Jetschke, S.; Unger, S.; Schwuchow, A.; Leich, M.; Kirchhof, J. Efficient Yb laser fibers with low photodarkening by optimization of the core composition. Opt. Express 2008, 16, 15540-15545. [CrossRef]

22. Leich, M.; Roepke, U.; Jetschke, S.; Unger, S.; Reichel, V.; Kirchhof, J. Non-isothermal bleaching of photodarkened Yb-doped fibers. Opt. Express 2009, 17, 12588-12593. [CrossRef]

23. Soderlund, M.J.; Ponsoda, J.J.M.I.; Koplow, J.P.; Honkanen, S. Heat-induced darkening and spectral broadening in photodarkened ytterbium-doped fiber under thermal cycling. Opt. Express 2009, 17, 9940-9946. [CrossRef]

24. Engholm, M.; Jelger, P.; Laurell, F.; Norin, L. Improved photodarkening resistivity in ytterbium-doped fiber lasers by cerium codoping. Opt. Lett. 2009, 34, 1285-1287. [CrossRef] 
25. Ponsoda, J.J.M.i.; Soderlund, M.; Koplow, J.; Koponen, J.; Iho, A.; Honkanen, S. Combined photodarkening and thermal bleaching measurement of an ytterbium-doped fiber. Proc. SPIE 2009, 7195, 7195D. [CrossRef]

26. Ponsoda, J.J.M.i.; Soderlund, M.; Koplow, J.; Koponen, J.; Honkanen, S. Photodarkening-induced increase of temperature in ytterbium-doped fibers. Proc. SPIE 2010, 7580, 75802N-1-75802N-7. [CrossRef]

27. Yoo, S.; Boyland, A.J.; Standish, R.J.; Sahu, J.K. Measurement of photodarkening in Yb-doped aluminosilicate fibres at elevated temperature. Electron. Lett. 2010, 46, 243-244. [CrossRef]

28. Ye, C.; Ponsoda, J.J.M.I.; Tervonen, A.; Honkanen, S. Refractive index change in ytterbium-doped fibers induced by photodarkening and thermal bleaching. Appl. Opt. 2010, 49, 5799-5805. [CrossRef] [PubMed]

29. Leich, M.; Jetschke, S.; Unger, S.; Kirchhof, J. Temperature influence on the photodarkening kinetics in Yb-doped silica fibers. J. Opt. Soc. Am. B-Opt. Phys. 2011, 28, 65-68. [CrossRef]

30. Ponsoda, J.J.M.i.; Ye, C.; Koplow, J.P.; Soderlund, M.J.; Koponen, J.J.; Honkanen, S. Analysis of temperature dependence of photodarkening in ytterbium-doped fibers. Opt. Eng. 2011, 50, 111610. [CrossRef]

31. Gebavi, H.; Taccheo, S.; Tregoat, D.; Monteville, A.; Robin, T. Photobleaching of photodarkening in ytterbium doped aluminosilicate fibers with $633 \mathrm{~nm}$ irradiation. Opt. Mater. Express 2012, 2, 1286-1291. [CrossRef]

32. Piccoli, R.; Robin, T.; Mechin, D.; Brand, T.; Klotzback, U.; Taccheo, S. Effective mitigation of photodarkening in Yb-doped lasers based on Al-silicate using UV/visible light. Proc. SPIE 2014, 8961, 896121. [CrossRef]

33. Zhao, N.; Xing, Y.B.; Li, J.M.; Liao, L.; Wang, Y.B.; Peng, J.G.; Yang, L.Y.; Dai, N.L.; Li, H.Q.; Li, J.Y. 793 nm pump induced photo-bleaching of photo-darkened $\mathrm{Yb}^{3+}$-doped fibers. Opt. Express 2015, 23, 25272-25278. [CrossRef] [PubMed]

34. Roepke, U.; Jetschke, S.; Leich, M. Linkage of photodarkening parameters to microscopic quantities in Yb-doped fiber material. J. Opt. Soc. Am. B-Opt. Phys. 2018, 35, 3126-3133. [CrossRef]

35. Zhao, N.; Li, W.; Li, J.; Zhou, G.; Li, J. Elimination of the Photodarkening Effect in an Yb-Doped Fiber Laser with Deuterium. J. Lightw. Technol. 2019, 37, 3021-3026. [CrossRef]

36. Zhao, N.; Peng, K.; Li, J.; Chu, Y.; Zhou, G.; Li, J. Photodarkening effect suppression in Yb-doped fiber through the nanoporous glass phase-separation fabrication method. Opt. Mater. Express 2019, 9, 1085-1094. [CrossRef]

37. Cao, R.; Chen, G.; Chen, Y.; Zhang, Z.; Lin, X.; Dai, B.; Yang, L.; Li, J.J.P.R. Effective suppression of the photodarkening effect in high-power $\mathrm{Yb}$-doped fiber amplifiers by $\mathrm{H}_{2}$ loading. Photonics Res. 2020, 8, 288-295. [CrossRef]

38. Ponsoda, J.J.M.i.; Soderlund, M.J.; Koplow, J.P.; Koponen, J.J.; Honkanen, S. Photodarkening-induced increase of fiber temperature. Appl. Opt. 2010, 49, 4139-4143. [CrossRef]

39. Leich, M.; Fiebrandt, J.; Schwuchow, A.; Jetschke, S.; Unger, S.; Jaeger, M.; Rothhardt, M.; Bartelt, H. Length distributed measurement of temperature effects in Yb-doped fibers during pumping. Opt. Eng. 2014, 53, 066101. [CrossRef]

40. Dong, L.; Archambault, J.L.; Reekie, L.; Russell, P.S.J.; Payne, D.N. Photoinduced absorption change in germanosilicate preformsEvidence for the color-center model of photosensitivity. Appl. Opt. 1995, 34, 3436-3440. [CrossRef]

41. Skuja, L. Defects in $\mathrm{SiO}_{2}$ and Related Dielectrics: Science and Technology; NATO Science Series; NATO: Erice, Italy, 2000.

42. Meltz, G.; Morey, W.W.; Glenn, W.H. Formation of bragg gratings in optical fibers by a transverse holographic method. Opt. Lett. 1989, 14, 823-825. [CrossRef]

43. Lee, Y.W.; Sinha, S.; Digonnet, A.J.F.; Byer, R.L.; Jiang, S. Measurement of high-photodarkening resistance in phosphate fiber doped with $12 \% \mathrm{Yb}_{2} \mathrm{O}_{3}$. Proc. SPIE 2008, 6873, 68731D. [CrossRef]

44. Poyntzwright, L.J.; Russell, P.S.J. Spontaneous relaxation processes in irradiated germanosilicate optical fibers. Electron. Lett. 1989, 25, 478-480. [CrossRef]

45. Griscom, D.L. Self-trapped holes in glassy silica: Basic science with relevance to photonics in space. Proc. SPIE 2011, 8164,816405 . [CrossRef]

46. Engholm, M.; Norin, L. Comment on "Photo darkening in Yb-doped aluminosilicate fibers induced by 488 nm irradiation". Opt. Lett. 2008, 33, 1216. [CrossRef] [PubMed]

47. Carlson, C.G.; Keister, K.E.; Dragic, P.D.; Croteau, A.; Eden, J.G. Photoexcitation of Yb-doped aluminosilicate fibers at 250 nm: Evidence for excitation transfer from oxygen deficiency centers to $\mathrm{Yb}^{3+}$. J. Opt. Soc. Am. B-Opt. Phys. 2010, 27, 2087-2094. [CrossRef]

48. Engholm, M.; Norin, L.; Aberg, D. Strong UV absorption and visible luminescence in ytterbium-doped aluminosilicate glass under UV excitation. Opt. Lett. 2007, 32, 3352-3354. [CrossRef] [PubMed]

49. Engholm, M.; Norin, L.; Hirt, C.; Fredrich-Thornton, S.T.; Petermann, K.; Huber, G. Quenching processes in Yb lasers; Correlation to the valence stability of the $\mathrm{Yb}$ ion. Proc. SPIE 2009, 7193, 71931U.

50. Shubin, A.V.; Yashkov, M.V.; Melkumov, M.A.; Smirnov, S.A.; Dianov, E.M. Photodarkening of alumosilicate and phosphosilicate Yb-doped fibers. In Proceedings of the European Conference on Lasers and Electro-Optics 2007, Munich, Germany, 17 June 2007.

51. Paschotta, R.; Tropper, A.C. Cooperative luminescence and absorption in Ytterbium-doped silica fiber and the fiber nonlinear transmission coefficient lambda $=980 \mathrm{~nm}$ with a regard to the Ytterbium ion-pairs' effect: Comment. Opt. Express 2006, 14, 6981-6982. [CrossRef] [PubMed]

52. Kir'yanov, A.V.; Barmenkov, Y.O. Cooperative luminescence and absorption in Ytterbium-doped silica fiber and the fiber nonlinear transmission coefficient lambda $=980 \mathrm{~nm}$ with a regard to the Ytterbium ion-pairs' effect: Reply. Opt. Express 2006, 14, 6983-6985. [CrossRef]

53. Hand, D.P.; Russell, P.S. Photoinduced refractive-index changes in germanosilicate fibers. Opt. Lett. 1990, 15, 102-104. [CrossRef] 
54. Koponen, J.; Soderlund, M.; Hoffman, H.J.; Kliner, D.A.V.; Koplow, J.P.; Hotoleanu, M. Photodarkening rate in Yb-doped silica fibers. Appl. Opt. 2008, 47, 1247-1256. [CrossRef] [PubMed]

55. Smith, A.V.; Smith, J.J. Mode instability thresholds for Tm-doped fiber amplifiers pumped at 790 nm. Opt. Express 2016, 2, 975-992. [CrossRef]

56. Mejia, E.B.; Talavera, D.V. Red (632.8-nm) attenuation by a copropagating $1175-\mathrm{nm}$ signal in Tm ${ }^{3+}$-doped optical fibers. Opt. Eng. 2007, 46, 105001. [CrossRef]

57. Schaudel, B.; Goldner, P.; Prassas, M.; Auzel, F. Cooperative luminescence as a probe of clustering in $\mathrm{Yb}^{3+}$ doped glasses. J. Alloy. Compd. 2000, 300, 443-449. [CrossRef]

58. Bonar, J.R.; Vermelho, M.V.D.; McLaughlin, A.J.; Marques, P.V.S.; Aitchison, J.S.; Martins, J.F.; Bezerra, A.G.; Gomes, A.S.L.; deAraujo, C.B. Blue light emission in thulium doped silica-on-silicon waveguides. Opt. Commun. 1997, 141, 137-140. [CrossRef]

59. Jenouvrier, P.; Boccardi, G.; Fick, J.; Jurdyc, A.M.; Langlet, M. Up-conversion emission in rare earth-doped $\mathrm{Y}_{2} \mathrm{Ti}_{2} \mathrm{O}_{7}$ sol-gel thin films. J. Lumin. 2005, 113, 291-300. [CrossRef]

60. Wang, G.; Qin, W.; Wang, L.; Wei, G.; Zhu, P.; Zhang, D.; Ding, F. Synthesis and upconversion luminescence properties of NaYF4: $\mathrm{Yb}^{3+} / \mathrm{Er}^{3+}$ microspheres. J. Rare Earths 2009, 27, 394-397. [CrossRef]

61. Auzel, F. Upconversion processes in coupled ion systems. J. Lumin. 1990, 45, 341-345. [CrossRef]

62. Peretti, R.; Gonnet, C.; Jurdyc, A.-M. Revisiting literature observations on photodarkening in $\mathrm{Yb}^{3+}$ doped fiber considering the possible presence of Tm impurities. J. Appl. Phys. 2012, 112, 093511. [CrossRef]

63. Jetschke, S.; Unger, S.; Schwuchow, A.; Leich, M.; Fiebrandt, J.; Jäger, M.; Kirchhof, J. Evidence of Tm impact in lowphotodarkening Yb-doped fibers. Opt. Express 2013, 21, 7590-7598. [CrossRef]

64. Simpson, D.A.; Gibbs, W.E.; Collins, S.F.; Blanc, W.; Dussardier, B.; Monnom, G.; Peterka, P.; Baxter, G.W. Visible and near infra-red up-conversion in $\mathrm{Tm}^{3+} / \mathrm{Yb}^{3+}$ co-doped silica fibers under $980 \mathrm{~nm}$ excitation. Opt. Express 2008, 16, 13781-13799. [CrossRef] [PubMed]

65. Jolly, A.; Vincont, C.; Pierre, C.; Boullet, J. Modelling the competition between photo-darkening and photo-bleaching effects in high-power ytterbium-doped fibre amplifiers. Appl. Phys. B-Lasers Opt. 2017, 123, 227. [CrossRef]

66. Otto, H.-J.; Modsching, N.; Jauregui, C.; Limpert, J.; Tuennermann, A. Impact of photodarkening on the mode instability threshold. Opt. Express 2015, 23, 15265-15277. [CrossRef]

67. Ward, B. Theory and modeling of photodarkening-induced quasi static degradation in fiber amplifiers. Opt. Express 2016, 24, 3488-3501. [CrossRef] [PubMed]

68. Jauregui, C.; Otto, H.-J.; Stutzki, F.; Limpert, J.; Tuennermann, A. Simplified modelling the mode instability threshold of high power fiber amplifiers in the presence of photodarkening. Opt. Express 2015, 23, 20203-20218. [CrossRef] [PubMed]

69. Li, N.; Yoo, S.; Yu, X.; Jain, D.; Sahu, J.K. Pump Power Depreciation by Photodarkening in Ytterbium-Doped Fibers and Amplifiers. IEEE Photonics Technol. Lett. 2014, 26, 115-118. [CrossRef]

70. Jetschke, S.; Schwuchow, A.; Unger, S.; Leich, M.; Jäger, M.; Kirchhof, J. Deactivation of $\mathrm{Yb}^{3+}$ ions due to photodarkening. Opt. Mater. Express 2013, 3, 452. [CrossRef]

71. Sceats, M.G.; Atkins, G.R.; Poole, S.B. Photolytic index changes in optical fibers. Annu. Rev. Mater. Sci. 1993, 23, 381-410. [CrossRef]

72. Brambilla, G.; Pruneri, V.; Reekie, L.; Paleari, A.; Chiodini, N.; Booth, H. High photosensitivity in $\mathrm{SnO}_{2}$ : $\mathrm{SiO}_{2}$ optical fibers. Fiber Integr. Opt. 2001, 20, 553-564. [CrossRef]

73. Gusarov, A.I.; Doyle, D.B. Contribution of photoinduced densification to refractive-index modulation in Bragg gratings written in Ge-doped silica fibers. Opt. Lett. 2000, 25, 872-874. [CrossRef]

74. Gusarov, A.I.; Doyle, D.B.; Berghmans, F.; Deparis, O. Analysis of photoinduced stress distribution in fiber Bragg gratings. Opt Lett. 1999, 24, 1334-1336. [CrossRef]

75. Taunay, T.; Niay, P.; Bernage, P.; Douay, M.; Xie, W.X.; Pureur, D.; Cordier, P.; Bayon, J.F.; Poignant, H.; Delevaque, E.; et al. Bragg grating inscriptions within strained monomode high NA germania-doped fibres: Part I. Experimentation. J. Phys. D-Appl. Phys. 1997, 30, 40-52. [CrossRef]

76. Hewlett, S.J.; Love, J.D.; Meltz, G.; Bailey, T.J.; Morey, W.W. Cladding-mode coupling characteristics of bragg gratings in depressed-cladding fiber. Electron. Lett. 1995, 31, 820-822. [CrossRef]

77. Oh, K.; Kim, J.M.; Seo, H.S.; Paek, U.C.; Kim, M.S.; Choi, B.H. Suppression of cladding mode coupling in Bragg grating using $\mathrm{Ge}_{2} \mathrm{O}-\mathrm{B}_{2} \mathrm{O}_{3}$ codoped photosensitive cladding optical fibre. Electron. Lett. 1999, 35, 423-424. [CrossRef]

78. Giles, C.R.; Desurvire, E. Modeling erbium-doped fiber amplifiers. J. Lightw. Technol. 1991, 9, 271-283. [CrossRef]

79. Hilaire, S.; Roy, P.; Pagnoux, D.; Bayart, D. Large mode $\mathrm{Er}^{3+}$-doped photonic crystal fibre amplifier for higly efficient amplification. In Proceedings of the European Conference on Optieal Colnmunieation, ECOC 2003, Rimini, Italy, 21-25 September 2003.

80. Cregan, R.F.; Knight, J.C.; Russell, P.S.; Roberts, P.J. Distribution of spontaneous emission from an Er ${ }^{3+}$-doped photonic crystal fiber. J. Lightw. Technol. 1999, 17, 2138-2141. [CrossRef]

81. Cucinotta, A.; Poli, F.; Selleri, S.; Vincetti, L.; Zoboli, M. Amplification properties of $\mathrm{Er}^{3+}$-doped photonic crystal fibers. J. Lightw. Technol. 2003, 21, 782-788. [CrossRef]

82. Rebolledo, M.A.; Jarabo, S. Erbium-doped silica fiber modeling with overlapping factors. Appl. Opt. 1994, 33, 5585-5593. [CrossRef] [PubMed]

83. Shugan, F.; Qiren, Z. Crystal Color Center Physics; Shanghai Jiaotong University Press: Shanghai, China, 1989; p. 14. (In Chinese) 
84. Greenwell, R.A.; Barnes, C.E.; Scott, D.M.; Biswas, D.R. Optical fibers in the adverse space environment-The Space Station. Proc. SPIE 1990, 1314, 100-104.

85. Soderlund, M.J.; Ponsoda, J.J.M.i.; Koplow, J.P.; Honkanen, S. Thermal bleaching of photodarkening-induced loss in ytterbiumdoped fibers. Opt. Lett. 2009, 34, 2637-2639. [CrossRef]

86. Thichda, B.; Berghmansa, B.F.; Decrétona, M.; Tomashuk, A.L.; Golant, K.M. Dedicated optical fibers for dosimetry based on radiation-induced attenuation: Experimental results. In Proceedings of the Europto Conference on Photonics for Space \& Radiation Environments, Florence, Italy, 7 December 1999; Volume 3872, pp. 36-42. [CrossRef]

87. Morita, Y.; Kawakami, W. Dose-rate effect on radiation-induced attenuation of pure silica core optical fibers. IEEE Trans. Nucl. Sci. 1989, 36, 584-590. [CrossRef]

88. Piccoli, R.; Gebavi, H.; Lablonde, L.; Cadier, B.; Robin, T.; Monteville, A.; le Goffic, O.; Landais, D.; Mechin, D.; Milanese, D.; et al Evidence of Photodarkening Mitigation in Yb-Doped Fiber Lasers by Low Power $405 \mathrm{~nm}$ Radiation. IEEE Photonics Technol. Lett. 2014, 26, 50-53. [CrossRef]

89. Dong, L.; Archambault, J.L.; Taylor, E.; Roe, M.P.; Reekie, L.; Russell, P.S.J. Photosensitivity in tantalum-doped silica optical fibers. J. Opt. Soc. Am. B-Opt. Phys. 1995, 12, 1747-1750. [CrossRef]

90. Gebavi, H.; Taccheo, S.; Lablonde, L.; Cadier, B.; Robin, T.; Mechin, D.; Tregoat, D. Mitigation of photodarkening phenomenon in fiber lasers by $633 \mathrm{~nm}$ light exposure. Opt. Lett. 2013, 38, 196-198. [CrossRef]

91. Atkins, G.R.; Ouellette, F. Reversible photodarkening and bleaching in TB ${ }^{3+}$-doped optical fibers. Opt. Lett. 1994, 19, 951-956. [CrossRef]

92. Jasapara, J.; Andrejco, M.; Digiovanni, D.; Windeler, R.J.I. Effect of Heat and $\mathrm{H}_{2}$ Gas on the Photo-Darkening of $\mathrm{Yb}^{3+}$ Fibers. In Proceedings of the Conference on Lasers and Electro-Optics 2006, Long Beach, CA, USA, 21-26 May 2006. [CrossRef]

93. Jetschke, S.; Leich, M.; Unger, S.; Roepke, U. Combined effect of Yb inversion and pump photons on photodarkening in Yb laser fibers: Experiments and model considerations. J. Opt. Soc. Am. B-Opt. Phys. 2019, 36, 2438-2444. [CrossRef]

94. Leich, M.; Jetschke, S.; Unger, S.; Kirchhof, J. Temperature dependence of photodarkening kinetics. Proc. SPIE 2010, 7580, 758009.

95. Taccheo, S.; Gebavi, H.; Monteville, A.; le Goffic, O.; Landais, D.; Mechin, D.; Tregoat, D.; Cadier, B.; Robin, T.; Milanese, D.; et al. Concentration dependence and self-similarity of photodarkening losses induced in $\mathrm{Yb}$-doped fibers by comparable excitation. Opt. Express 2011, 19, 19340-19345. [CrossRef]

96. Laperle, P.; Desbiens, L.; le Foulgoc, K.; Drolet, M.; Deladurantaye, P.; Proulx, A.; Taillon, Y. Modeling the photodegradation of large mode area Yb-doped fiber power amplifiers. Proc. SPIE 2009, 7195, 71952C.

97. Laperle, P. Etude de Lasers a Fibre Emettant a $480 \mathrm{~nm}$ et du Phenomene de Coloration Dans la Fibre de ZBLAN Dopee au Thulium. Ph.D. Thesis, Universite Laval, Quebec City, QC, Canada, 2003.

98. Jelger, P.; Engholm, M.; Norin, L.; Laurell, F. Degradation-resistant lasing at $980 \mathrm{~nm}$ in a Yb/Ce/Al-doped silica fiber. J. Opt. Soc. Am. B-Opt. Phys. 2010, 27, 338-342. [CrossRef]

99. Engholm, M.; Norin, L. Ytterbium-doped fibers co-doped with Cerium; Next generation of fibers for high power fiber lasers? Proc. SPIE 2010, 7580, 758008.

100. Vargin, V.V.; Osadchaya, G.A.J.G. Cerium dioxide as a fining agent and decolorizer for glass. Glass Ceram. 1960, 17, 78-82. [CrossRef]

101. Kilabayashi, T.; Ikeda, M.; Nakai, M.; Sakai, T.; Himeno, K.; Ohashi, K. Population inversion factor dependence of photodarkening of $\mathrm{Yb}$-doped fibers and its suppression by highly aluminum doping. In Proceedings of the 2006 Optical Fiber Communication Conference and the National Fiber Optic Engineers Conference, Anaheim, CA, USA, 5-10 March 2006; Volume 106, pp. 9-12. [CrossRef]

102. Arai, K.; Namikawa, H.; Kumata, K.; Honda, T.; Ishii, Y.; Handa, T.J. Aluminum or phosphorus co-doping effects on the fluorescence and structural properties of neodymium-doped silica glass. Appl. Phys. 1986, 59, 3430-3436. [CrossRef]

103. Peretti, R.; Jurdyc, A.M.; Jacquier, B.; Blanc, W.; Dussardier, B. Spectroscopic signature of phosphate crystallization in erbiumdoped optical fibre preforms. Opt. Mater. 2011, 33, 835-838. [CrossRef]

104. Deschamps, T.; Ollier, N.; Vezin, H.; Gonnet, C. Clusters dissolution of $\mathrm{Yb}^{3+}$ in codoped $\mathrm{SiO}_{2}-\mathrm{Al}_{2} \mathrm{O}_{3}-\mathrm{P}_{2} \mathrm{O}_{5}$ glass fiber and its relevance to photodarkening. J. Chem. Phys. 2012, 136, 372. [CrossRef]

105. Gavrilovic, P.; Goyal, A.K.; Po, H.; Singh, S. Laser Composition for Preventing Photo-Induced Damage. U.S. Patent No. 6,154,598, 28 November 2000.

106. Jetschke, S.; Leich, M.; Unger, S.; Schwuchow, A.; Kirchhof, J. Influence of Tm- or Er-codoping on the photodarkening kinetics in $\mathrm{Yb}$ fibers. Opt. Express 2011, 19, 14473-14478. [CrossRef] [PubMed]

107. Deschamps, T.; Vezin, H.; Gonnet, C.; Ollier, N. Evidence of AlOHC responsible for the radiation-induced darkening in $\mathrm{Yb}$ doped fiber. Opt. Express 2013, 21, 8382-8392. [CrossRef]

108. Dragic, P.D.; Carlson, C.G.; Croteau, A. Characterization of defect luminescence in Yb doped silica fibers: Part INBOHC. Opt. Express 2008, 16, 4688-4697. [CrossRef]

109. Vitiello, M.; Lopez, N.; Illas, F.; Pacchioni, G. H-2 cracking at $\mathrm{SiO}_{2}$ defect centers. J. Phys. Chem. A 2000, 104, 4674-4684. [CrossRef]

110. Xing, Y.-B.; Liu, Y.-Z.; Zhao, N.; Cao, R.-T.; Wang, Y.-B.; Yang, Y.; Peng, J.-G.; Li, H.-Q.; Yang, L.-Y.; Dai, N.-L.; et al. Radical passive bleaching of Tm-doped silica fiber with deuterium. Opt. Lett. 2018, 43, 1075-1078. [CrossRef] 